\title{
可见光/镍协同催化烯烃和炔烃双官能团化反应研究进展
}

\author{
徐䂞王方陈凡朱圣卿* 储玲玲*
}

(东华大学化学化工与生物工程学院 先进低维材料中心 上海 201620)

\begin{abstract}
摘要 可见光氧化还原催化与金属镍催化的联姻, 使得在极为温和条件下构建挑战性化学键成为可能. 然而, 大多数 协同催化体系只能构建单一的碳-碳键或碳一杂原子键. 近些年来, 可见光/镍协同催化在烯烃及炔烃分子间双官能团化 反应领域引起了广泛关注. 该协同催化级联模式可以一步构建多个化学键，为复杂结构单元的快速高效构筑提供了温 和且高选择性的方法. 对可见光/镍协同催化烯烃和炔烃分子间双官能团化反应的最新研究进展进行了概述.

关键词＼cjkstart可见光催化；镍催化；协同催化；烯烃；炔烃；双官能团化
\end{abstract}

\section{Recent Advances in Photoredox/Nickel Dual-Catalyzed Difunctionalization of Alkenes and Alkynes}

\author{
Xu, Lei Wang, Fang Chen, Fan Zhu, Shengqing* Chu, Lingling* \\ (Center for Advanced Low-Dimension Materials, College of Chemistry, Chemical Engineering and \\ Biotechnology, Donghua University, Shanghai 201620)
}

\begin{abstract}
The merger of visible-light photoredox catalysis and nickel catalysis makes it possible to forge challenging chemical bonds under mild conditions. Nevertheless, most of these transformations only construct a single carbon-carbon bond or carbon-heteroatom bond in one operation. In recent years, photoredox/nickel dual catalysis has attracted widespread attention in the field of catalytic difunctionalization of alkenes and alkynes. The synergistic cascade mode enables the construction of multiple chemical bonds in one single pot, providing a mild, efficient and selective protocol for the rapid assembly of complex structural motifs. The latest progress in the photoredox/nickel dual-catalyzed difunctionalization reactions of olefins and alkynes is summarized.

Keywords photoredox catalysis; nickel catalysis; synergistic catalysis; alkene; alkyne; difunctionalization
\end{abstract}

过渡金属催化碳一碳键或碳-杂原子键的构筑是合 成化学领域的核心研究课题之一. 在众多过渡金属催化 剂中，镍催化剂因其低成本、低毒性及独特的催化活性 而受到化学家越来越多的关注 ${ }^{[1-4]}$. 镍催化剂展现出的 丰富价态 $\left(\mathrm{Ni}^{0} / \mathrm{Ni}^{\mathrm{I}} / \mathrm{Ni}^{\mathrm{II}} / \mathrm{Ni}^{\mathrm{III}} / \mathrm{Ni}^{i \mathrm{~V}}\right)$ 以及 $\beta$-氢消除能垒高等 特性, 使其在 $\mathrm{C}\left(\mathrm{sp}^{3}\right)$ 类型交叉偶联领域展现出巨大的潜 力 $^{[5-6]}$. 近些年来, 可见光氧化还原催化 ${ }^{[7-10]}$ 与镍催化的 联姻进一步推动了镍催化交叉偶联反应的快速发展, 在 极其温和的反应条件下实现了单一催化循环难以实现 的挑战性转化 ${ }^{[11-15]}$. 然而, 这些策略主要限于单一碳碳键或碳一杂原子键的构建. 催化交叉偶联串联反应的 发展可以从简单的原料出发快速构建复杂分子骨架, 带
来更高的原子经济性和更强的操作性 ${ }^{[16]}$.

烯烃和炔烃是一类简单易得的大宗化工原料，在医 药及材料等众多领域都有广泛应用. 催化烯烃和炔烃分 子间双官能团化反应可以一锅法构建两个连续的化学 键, 实现复杂结构单元的快速高效构建, 对于提高合成 效率具有重要的意义 ${ }^{[17-24]}$. 近些年来, 该领域取得了诸 多重要的研究进展, 然而传统的过渡金属催化双电子反 应模式依赖于有机金属试剂的使用、较高的反应温度或 者昂贵的金属催化剂等, 为该领域的发展带来诸多挑 战. 特别是对于非活化烯烃，由于烷基金属中间体易发 生 $\beta$-氢消除，很大程度上限制了 $\mathrm{C}\left(\mathrm{sp}^{3}\right)$-杂化类型试剂的 使用 ${ }^{[25]}$. 在这种研究背景下, 自由基介导的交叉偶联串

* Corresponding authors. E-mail: lingling.chu1@dhu.edu.cn; zhusq@dhu.edu.cn

Received September 1, 2021; revised September 18, 2021; published online September 29, 2021.

Project supported by the National Natural Science Foundation of China (Nos. 21991123, 21971036, 21901036), the Fundamental Research Funds for the Central Universities and the Graduate Student Innovation Fund of Donghua University (No. CUSF-DH-D-2020057).

国家自然科学基金(Nos. 21991123, 21971036, 21901036)、中央高校基本科研业务费专项资金和东华大学研究生创新基金(No. CUSF-DH-D-2020057) 资助项目. 
联模式为这些挑战提供了新的解决方案 ${ }^{[26-31]}$. 镍催化剂 在自由基介导烯烃的双官能团化反应中展现了卓越的 催化活性 ${ }^{[22,31-33]}$, 为传统的双电子催化模式提供了很好 的补充. 但是, 这些转化很大程度上还是依赖化学计量 的金属试剂或者金属还原剂进行的. 可见光/镍协同催 化的发展为自由基介导烯/炔烃双能团化反应带来新的 契机，成为一个卓有成效的探索领域.

过去的几年里, 可见光/镍协同催化烯烃和炔烃官 能团化转化反应得到了快速发展, 已经成为构建复杂结 构单元的温和高效的合成方法之一 ${ }^{[14-15,34]}$. 本文将从可 见光/镍协同催化烯烃双官能团化反应和炔烃分子间双 官能团化反应等方面介绍该领域的研究进展.

为了方便读者阅读, 在正式论述之前, 我们对可见 光/镍协同催化烯/炔烃双官能团化反应的常见催化路径 做简要论述. 如 Scheme 1 所示, 该协同催化体系一般涉 及两个相互螯合的催化循环, 由激发态光催化剂与偶联 子 $\mathrm{A}-\mathrm{X}$ 发生单电子转移(SET)生成自由基 I 来启动. 自 由基 I 可与烯烃、炔烃等发生自由基加成, 生成相应的 烷基或烯基自由基 II. 此时, 低价镍如 $\mathrm{Ni}(0)$ 捕获该自由 基 II 生成烷基-Ni(I)或烯基-Ni(I)物种 III，其进一步与偶 联子 $\mathrm{B}-\mathrm{Y}$ 发生氧化加成得到高价镍 $\mathrm{Ni}(\mathrm{III})$ 物种. 该 $\mathrm{Ni}(\mathrm{III})$ 物种发生快速还原消除生成双官能团化产物 $\mathbf{V}$ 和 $\mathrm{Ni}(\mathrm{I})$ 物种 VI. 最后, 还原态光催化剂 $[\mathrm{PC}]^{-}$与 $\mathrm{Ni}(\mathrm{I})$ 物种 发生另一单电子转移, 释放基态光催化剂 [PC]和 $\mathrm{Ni}(0)$, 完成可见光和金属镍两个催化循环(Scheme 1). 该协同 催化模式中, 通过调控光催化循环和镍催化循环可以实 现底物的选择性活化, 而两个循环的相互螯合又为反应 的选择性调控提供新的契机, 实现单一催化循环难以实 现的转化. 多数情况下, 激发态光催化剂发生还原淬灭 启动催化循环. 但是在少数反应体系中, 激发态光催化 剂可被还原剂氧化淬灭. Scheme 1 也展示了该体系中常 用的光催化剂结构.

\section{1 可见光/镍催化烯烃双官能团化反应}

\section{1 烯烃两组分双官能团化反应}

催化烯烃分子内双官能团化反应可以高效构建碳 环、杂环等环系骨架, 在复杂天然产物及药物分子的合 成中有着重要的应用[35].

2015 年, Jamison 等 ${ }^{[36]}$ 利用 $\mathrm{Ru}(\mathrm{bpy})_{3}\left(\mathrm{PF}_{6}\right)_{2}$ 作为光催 化剂、 $\mathrm{Ni}(\mathrm{cod})_{2}$ 为镍催化剂、氮杂环卡宾为配体, 在室 温下实现了光促 2-碘乙酰苯胺与末端烯烃高区域选择 性环化反应, 合成了一系列二氢吲哚化合物(Scheme 2). 该光促镍催化体系反应条件温和, 对多类型官能团如杂 环和羰基等都能很好地兼容. 芳基或烷基取代的末端烯 烃都能顺利参与反应. 关于反应机理, 作者提出了涉及

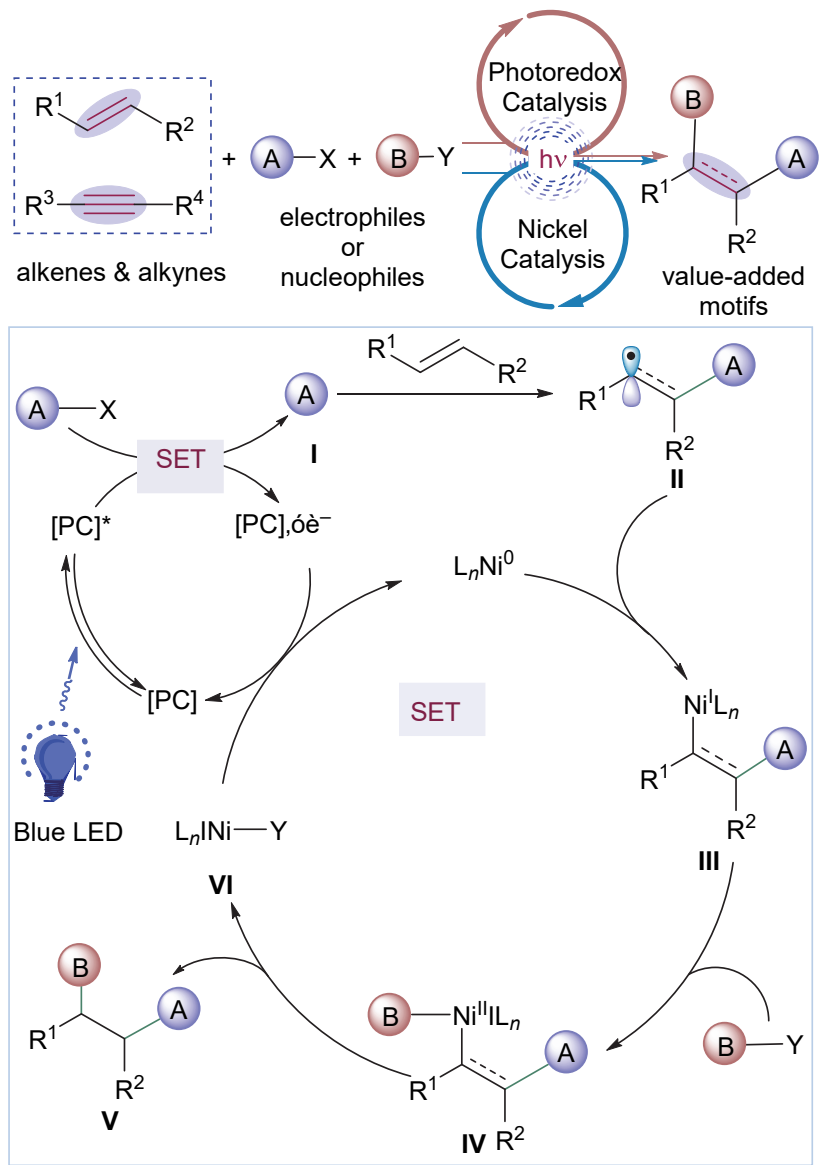

Commonly employed photocatalysts
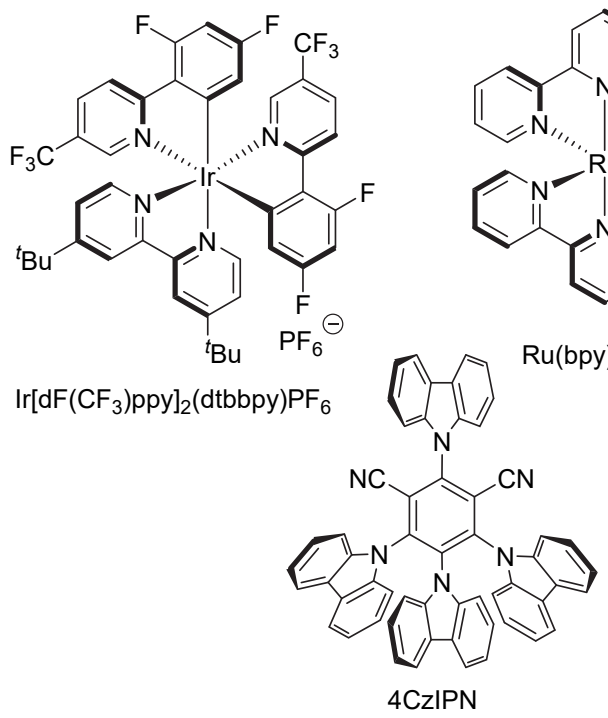

图式 1 可见光/镍协同催化烯烃和炔烃双官能团化反应 Scheme 1 Photoredox/nickel dual-catalyzed difunctionalizations of alkenes and alkynes

$\mathrm{Ni}(0) / \mathrm{Ni}(\mathrm{I}) / \mathrm{Ni}(\mathrm{II}) / \mathrm{Ni}(\mathrm{III})$ 的双催化循环机制. 如 Scheme 2 所示, 碘乙酰苯胺与 $\mathrm{Ni}(0)$ 发生氧化加成得到 $\mathrm{Ar}-\mathrm{Ni}(\mathrm{II})$ 中间体 I, 该镍物种与烯烃迁移插入生成 alkyl-Ni(II)物 种 III. alkyl-Ni(II)物种 III 与邻位芳胺发生配体交换的 同时，与激发态光催化剂* $\mathrm{Ru}$ 发生单电子转移生成氧化 
态 $\mathrm{Ni}(\mathrm{III})$ 物种 $\mathbf{I V}$ 和 $\mathrm{Ru}(\mathrm{II})$. 接下来, Ni(III)物种 IV 发生 快速还原消除得到二氢吲哚产物和 $\mathrm{Ni}(\mathrm{I})$ 物种 $\mathbf{V}$. 最后, 还原性 $\mathrm{Ru}(\mathrm{II})$ 催化剂和 $\mathrm{Ni}(\mathrm{I})$ 物种 $\mathbf{V}$ 发生单电子转移, 得 到相应的零价镍和基态光催化剂, 从而完成整个催化循 环. 作者发现, 氮杂环卡宾配体 IPr 的使用对 $\mathrm{Ar}-\mathrm{Ni}(\mathrm{II})$ 物种与烯烃高选择性插入以及抑制 alkyl-Ni(II)中间体的 $\beta-\mathrm{H}$ 消除起着至关重要的作用.

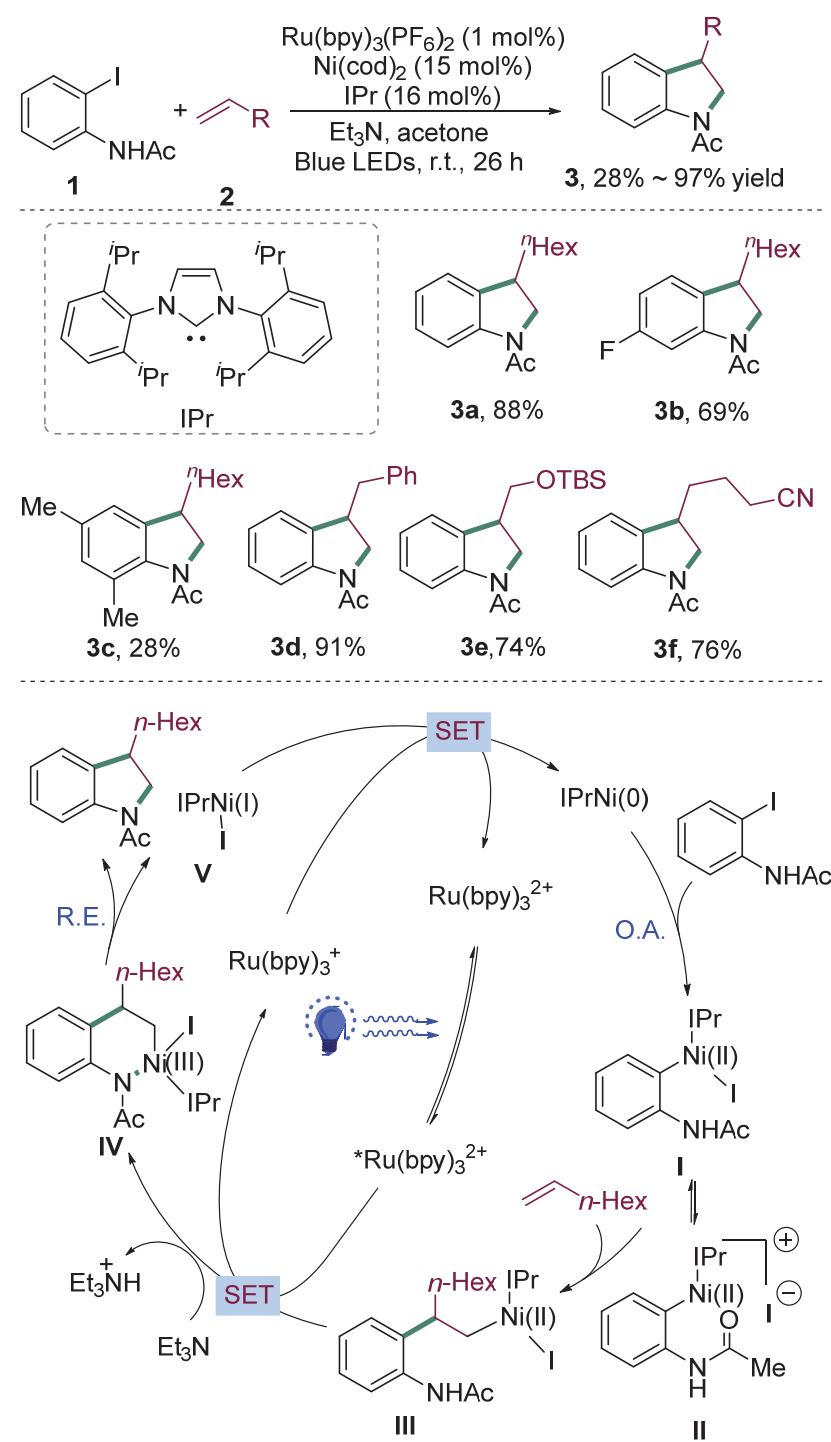

图式 2 光镍催化烯烃与芳胺环合反应

Scheme 2 Cyclization reaction of aromatic amines with alkenes by dual photoredox/nickel catalysis

乙烯分子是最小的烯烃结构单元, 其催化双官能团 化反应一直是合成化学中的一大挑战 ${ }^{[37]} .2019$ 年, $\mathrm{Wu}$ 和 Lan 等 ${ }^{[38]}$ 首次报道了可见光氧化还原/金属镍协同催化 乙烯分子与芳基卤化物的多芳基偶联反应(Scheme 3). 该反应体系可通过调控光催化剂结构和反应条件, 实现 1,2-二芳基乙烷、1,4-二芳基丁烷及 2,3-二芳基丁烷等化 合物的发散性合成. 以 $\mathrm{Ru}(\mathrm{bpy})_{2} \bullet 6 \mathrm{H}_{2} \mathrm{O}$ 为光催化剂时,
得到单乙烯分子 1,2 -双芳基化产物; 而以 $\left[\operatorname{Ir}(\mathrm{ppy})_{2}\right.$ (dtbbpy)] $\mathrm{PF}_{6}$ 为光催化剂时, 得到两个乙烯分子双芳基 化产物. 机理实验和密度泛函(DFT)计算表明，该反应 可能经历芳基镍物种与乙烯分子的迁移插入过程，不同 的激发态光催化剂(Ru-基和 Ir-基)可有效调控金属镍物 种的启动价态 $[\mathrm{Ni}(0)$ 和 $\mathrm{Ni}(\mathrm{I})]$, 从而实现发散性转化.

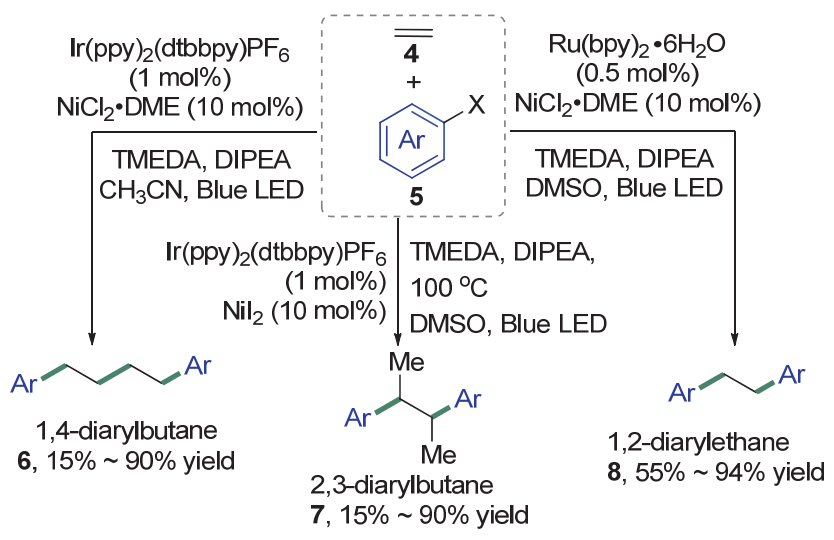

图式 3 光镍催化乙烯分子发散性双官能化反应 Scheme 3 Divergent difunctionalization of ethylene via dual nickel/photoredox catalysis

分子内自由基环化是构建环状骨架的有效方法之 - ${ }^{[39] .} 2019$ 年, Molander 等 ${ }^{[40]}$ 基于分子内自由基环化与 镍催化交叉偶联串联的策略, 利用 $\operatorname{Ir}\left[\mathrm{dF}\left(\mathrm{CF}_{3}\right) \text { ppy }\right]_{2}(\mathrm{bpy})-$ $\mathrm{PF}_{6}$ 作为光催化剂、 $\mathrm{Ni}(\mathrm{dMeObpy}) \mathrm{Br}_{2} \cdot 2 \mathrm{H}_{2} \mathrm{O}$ 作为镍催化 剂，实现了光镍协同催化的未活化烯烃与芳基澳的级联 酰胺芳基化反应，快速构建了一系列具有重要生物活性 的吡咯烷酮等含氮杂环化合物 (Scheme 4). 不同于 Jamison 等 ${ }^{[36]}$ 催化体系, 该协同反应通过光氧化还原质 子偶合电子转移(PCET)直接活化烯基酰胺的 $\mathrm{N}-\mathrm{H}$ 键生 成相应的氮自由基来启动 ${ }^{[41]}$, 该亲电性氮自由基与底 物中的不饱和双键发生快速的 5-exo 自由基环化, 生成 相应的烷基自由基. 在镍催化剂协同参与下，烷基自由 基与芳基溴发生交叉偶联, 进而得到相应的五元氮杂环 化合物. 该反应具有较好的底物适用范围, 适用于一系 列烯基酰胺、芳基溴以及杂环芳基溴底物，展现了优秀 的官能团兼容性. 该反应也能进一步拓展至烯基氨基甲 酸酯和腿, 为不同类型五元氮杂环的快速构建提供了新 颖高效的合成方法. 作者也对反应的机理进行了深入的 探讨，一系列苂光淬灭实验、自由基环化速率的测定及 氧化还原电势的测定等机理实验的结果有力支持了可 见光/镍协同催化对该自由基环化串联过程的决定作用.

在此工作基础上, Molander 等 ${ }^{[42]}$ 随后利用酰氯作为 偶联子，报道了光/镍协同催化未活化烯烃分子间级联 胺化酰基化反应，快速构建了一系列具有重要生物活性 的吡咯烷酮等含氮杂环化合物(Scheme 5). 该反应条件 


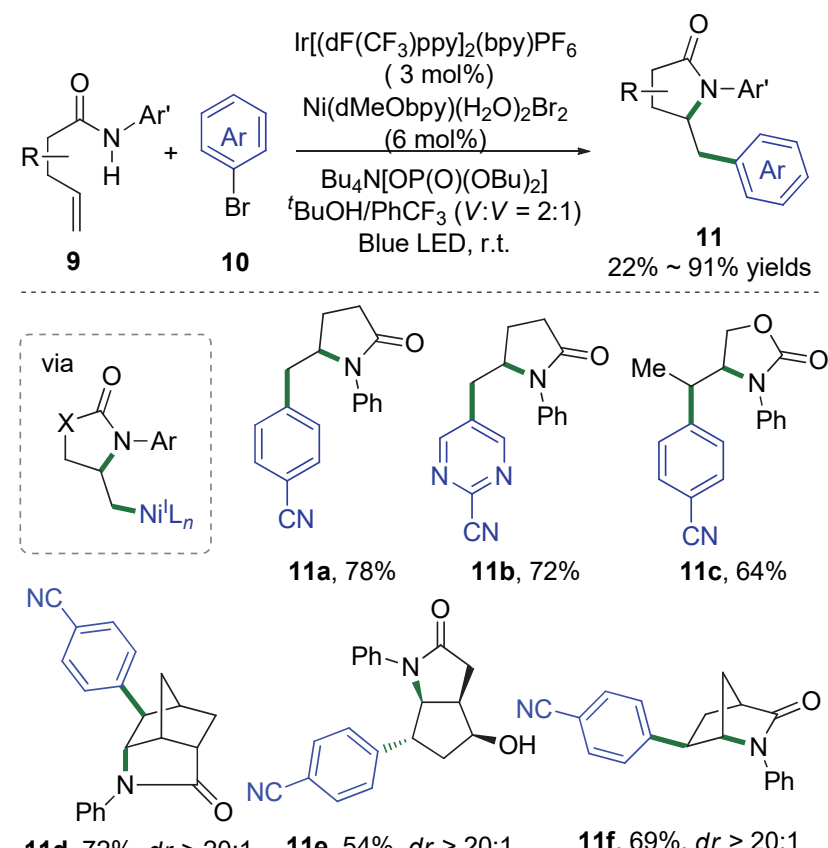

11d, $72 \%, d r>20: 1 \quad$ 11e, $54 \%, d r>20: 1 \quad$ 11f, $69 \%, d r>20: 1$

图式 4 光镍催化未活化烯烃级联酰胺芳基化反应

Scheme 4 Cascade amidoarylation of unactivated olefins via dual nickel/photoredox catalysis

较为温和, 展现了优秀的底物适用性和非对映选择性. 反应条件和反应历程同上述级联酰胺芳基化反应都较 为类似 ${ }^{[41]}$.

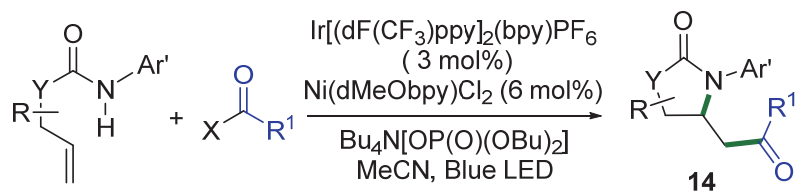

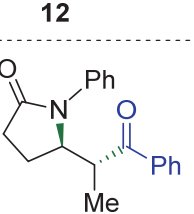

14a, $75 \%, d r>20: 1$

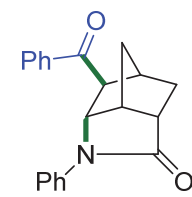

$14 d, 61 \%, d r>20: 1$
13

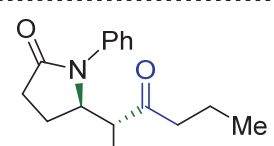

$\mathrm{Me}$

$14 \mathrm{~b}, 49 \%, d r=4: 1$

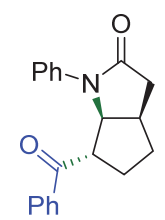

$14 \mathrm{e}, 61 \%, d r>20: 1$

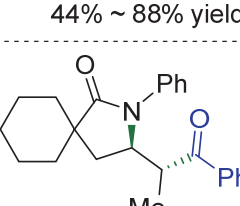

Me
$64 \%$

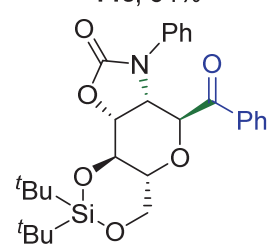

14f, $68 \%, d r>20: 1$
图式 5 光镍催化未活化烯烃非对映选择性氮酰化反应

Scheme 5 Diastereoselective amidoacylation of unactivated olefins via dual nickel/photoredox catalysis

Overman 等[43]利用可见光/镍协同催化实现了高烯 丙基草酸铯与芳基碘化物的分子内环化-交叉偶联串联 反应，构建了一系列官能团化的 $\gamma$-丁内酯化合物 (Scheme 6). 该协同反应体系条件温和, 一系列链状、环 状的高烯丙基草酸铯盐都能较好地适用, 与相应的芳基
碘、烯基碘发生环化串联反应. 该反应是由碳自由基分 子内环化启动. 烯烃中的草酸铯盐基团在激发态光催化 剂作用下发生单电子氧化生成羧基自由基，脱除一分子 $\mathrm{CO}_{2}$ 后得到烷氧基羰基自由基，该自由基与烯烃发生分 子内 5-exo 环化, 进而在镍催化剂作用下与芳基碘发生 交叉偶联. 根据文献报道, 羧基自由基通常容易脱除两 分子 $\mathrm{CO}_{2}$ 得到更稳定的烷基自由基. 而该反应成功的关 键在于烷氧基羰基自由基的分子内 5-exo 环化过程比其 脱除第二分子 $\mathrm{CO}_{2}$ 的反应速率更快. 作者发现，类似的 6-exo 自由基环化-交叉偶联的反应效率明显降低.

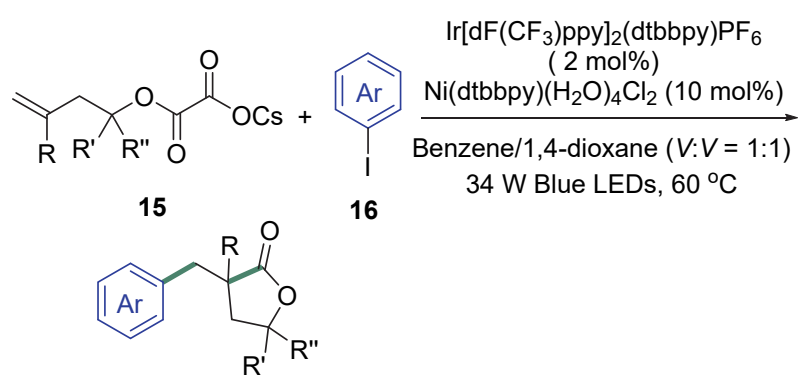

$17,62 \% \sim 88 \%$ yield

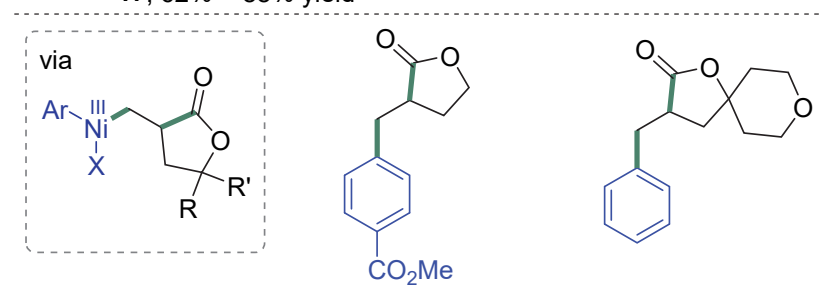

$17 a, 73 \% \quad 17 b, 76 \%$

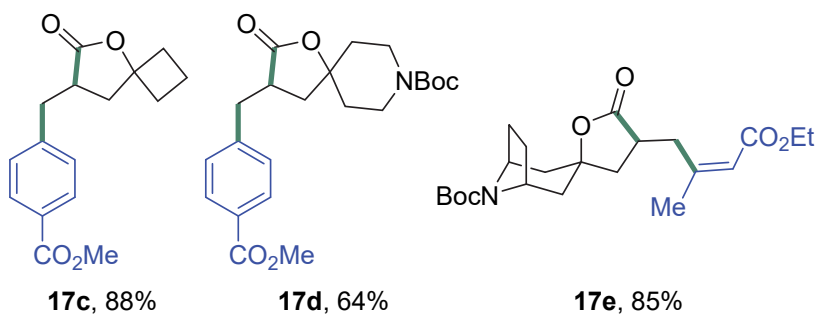

图式 6 光镍催化烷氧基羰基环化交叉偶联级联反应 Scheme 6 Alkoxycarbonyl radical cyclization cross-coupling cascade reaction via dual nickel/photoredox catalysis

\section{2 烯烃三组分双官能团化反应}

随着可见光/金属协同催化的快速发展，近三年来， 利用光镍协同催化调控烯烃三组分双官能团化反应也 受到了极大关注.

\subsection{1 烯烃三组分双碳官能团化反应}

2019 年, 储玲玲等 ${ }^{[44]}$ 利用叔醇草酸铯盐作为烷基 自由基前体, 芳基卤代物作为亲电试剂, $\operatorname{Ir}\left[\mathrm{dF}\left(\mathrm{CF}_{3}\right)\right.$ ppy $]_{2}$ (bpy) $\mathrm{PF}_{6}$ 作为光催化剂、 $\mathrm{NiCl}_{2} \bullet \mathrm{DME}$ 作为镍催化剂, 实现了光镍协同催化烯烃分子间 1,2-烷基芳基化反应 (Scheme 7). 该反应条件温和，官能团兼容性好，对三 个反应组分烯烃、(杂)芳基卤化物以及叔醇草酸铯盐均 


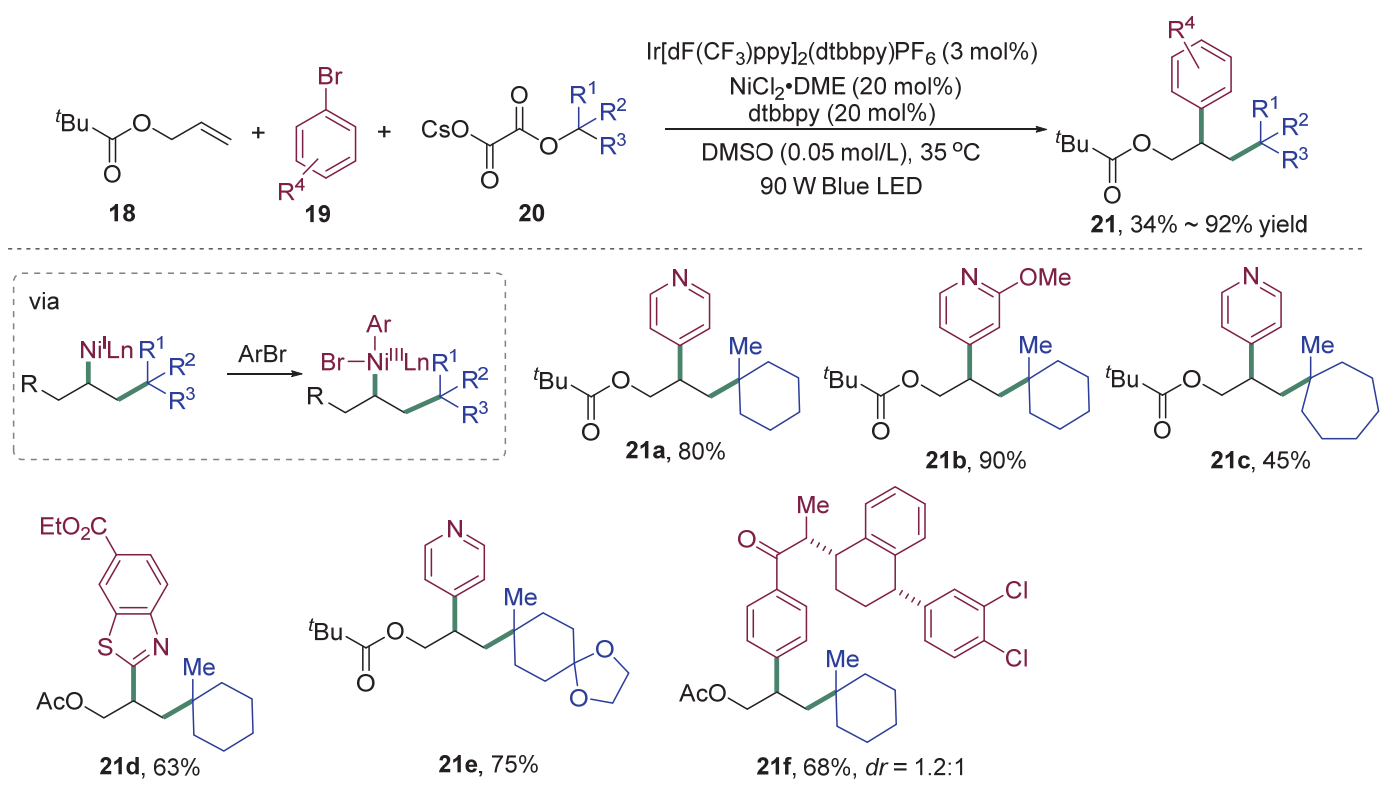

图式 7 光镍催化烯烃三组分烷基芳基化反应

Scheme 7 Three-component alkylarylation of alkenes via dual nickel/photoredox catalysis

有很好的底物适用性. 除缺电子烯烃外, 富电子烯烃如 烯基醚、烯基硫醚以及非活化烯烃也能够发生相应的烷 基芳基化, 且区域选择性单一. 遗憾的是, 烷基自由基 前体仅限于叔醇衍生物, 相应的仲醇及伯醇草酸铯盐主 要得到其与芳基卤化物交叉偶联的副产物. 机理研究表 明, 该反应由激发态光催化剂单电子氧化叔醇草酸铯盐 生成相应的叔碳自由基启动. 在位阻因素影响下, 叔碳 自由基区域选择性地加成末端烯烃, 得到的仲碳烷基自 由基被镍物种捕获，继而与芳基溴发生交叉偶联.

2019 年, Nevado 等 ${ }^{[45]}$ 采用类似的可见光/镍协同催 化策略, 利用烷基硅酸盐为烷基自由基前体, $\mathrm{Ru}(\mathrm{bpy})_{3}$ $\mathrm{Cl}_{2} \cdot 6 \mathrm{H}_{2} \mathrm{O}$ 作为光催化剂, 实现了缺电子烯烃与芳基碘化 物的 1,2-烷基芳基化反应(Scheme 8). 该反应具有较好 的官能团兼容性和底物适用性，一系列芳基碘化物、三 级甚至二级硅酸盐均能较好适用. 三个偶联组分之间的 物质的量之比对于芳基烷基化产物的形成至关重要, 使 用过量的烯烃和硅酸烷基酯可以有效减少硅酸烷基酯 和芳基碘两组分的交叉偶联副反应.

同时, Molander 等 ${ }^{[46]}$ 也报道了可见光/镍催化协同 催化烯基硼酸酯与烷基三氟硼酸盐和芳基澳的 1,2-烷基 芳基化反应，一锅法高效构建了高度官能团化的苄基硼 酯化合物(Scheme 9). 该反应条件温和，官能团兼容性 优秀, 仲碳、叔碳烷基三氟硼酸盐、各类芳基澳、杂环 芳基溴都能顺利地参与反应，芳环上含有的 $\mathrm{SiMe}_{3}$, Bpin, I 及 OTf 等基团均能较好地兼容. 反应构建的苄基 硼酯化合物是一类重要的合成砌块, 可进一步发生各类 转化. 作者也成功将其应用到生物活性分子 TK-666 衍 生物的合成中. 该反应也能进一步拓展到其他类型的缺

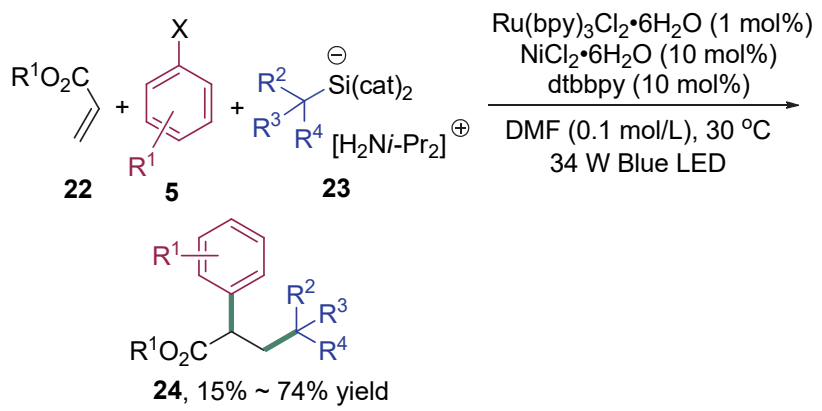<smiles>CC(C)(C)OC(=O)C(CC1CCCCC1)c1ccc(C(CC2CCCCC2)C(=O)OCc2ccc(C(C)(C)C)cc2)cc1</smiles>

$\mathbf{2 4 a}, 68 \%$

24b, $71 \%$

24c, $67 \%$

图式 8 光镍催化烯烃三组分双碳官能化反应

Scheme 8 Three-component carbofunctionalization of alkenes via dual nickel/photoredox catalysis

电子烯烃. 一系列自由基钟、自由基环化等机理实验表 明，该反应经历烷基自由基与烯基硼酸酯自由基加成, 得到更为稳定的 $\alpha$-硼烷自由基, 随后在镍参与下与芳基 溴发生交叉偶联.

2020 年, Aggarwal 等 ${ }^{[47]}$ 利用烷基羧酸为自由基前 体, 以 $4 \mathrm{CzIPN}$ 为光催化剂, 发展了光/镍协同催化乙烯 基硓酸酯与芳基碘的三组分脱羧交叉偶联反应，构建了 官能团化烷基硼酸酯化合物(Scheme 10). 反应具有优 秀的官能团兼容性和化学、区域选择性. 值得指出的是, 链状、环状的二级/三级 $\alpha$-氨基酸及 $\alpha$-含氧酸都能顺利 参与反应，以中等到良好的产率得到相应的烷基硼酸酯 


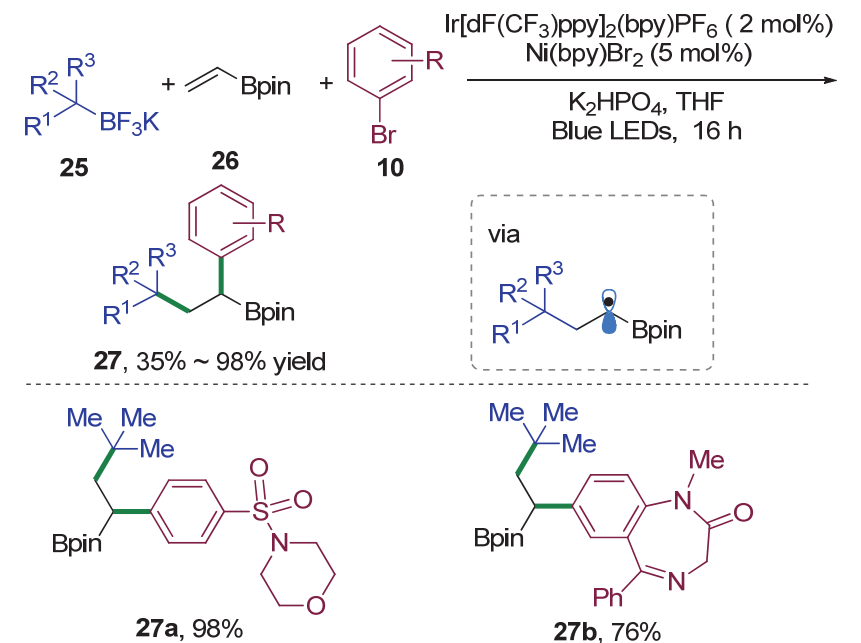

27b, $76 \%$<smiles>CC(C)(C)CC(Br)c1cnc(Cl)c(C#N)c1</smiles>

27c, $73 \%$

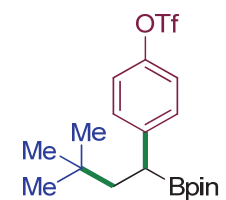

27d, $64 \%$

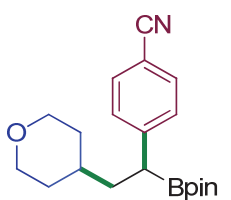

27e, $54 \%$
图式 9 光镍催化烯烃嗍酸酯烷基芳基化反应

Scheme 9 Alkylarylation of vinyl boronic esters via dual nickel/photoredox catalysis
产物. 与此同时，Martin 等[48]利用可见光/镍协同催化还 原偶联策略，以四甲基乙二胺(TMEDA)为还原剂，发展 了乙烯基嗍酸酯、叔丁基溴及芳基溴化物三组分还原 1,2-烷基芳基化反应(Scheme 11). 该还原反应体系对芳 基卤化物和三级烷基澳展现出良好的底物适用性. 同上 述氧化还原中性体系不同，该反应由光促还原淬灭途径 启动：四甲基乙二胺(TMEDA)淬灭激发态光催化剂 *4CzIPN，生成的还原性催化剂与烷基澳发生单电子转 移生成相应的烷基自由基. 遗憾的是，一级、二级烷基 溴不适用于该反应.

最近，储玲玲等 ${ }^{[49]}$ 发展了可见光/镍协同催化乙烯 基硼酸酯、烷基草酸铯盐和芳基溴化物的三组分串联反 应(Scheme 12). 该反应中, 光镍催化下乙烯基硼酯发生 1,2-烷基芳基化反应，生成的芐基硼酯产物在弱碱性条 件下发生脱硼得到相应的烷烃产物, 实现了形式上乙烯 分子 1,2-烷基芳基化反应. 反应对多种叔醇衍生的草酸 铯盐以及缺电子(杂)芳基澳都有着很好的底物适用性.

2020 年，袁伟明课题组 ${ }^{[50]}$ 利用 $\alpha$-硅基烷基胺为烷 基自由基前体, $\operatorname{Ir}(\mathrm{ppy})_{2}(\mathrm{bpy}) \mathrm{PF}_{6}$ 为光催化剂, 发展了可 见光/镍协同催化缺电子烯烃和芳基碘分子间 1,2-碳芳 基化反应(Scheme 13). 值得指出的是，该协同反应体系

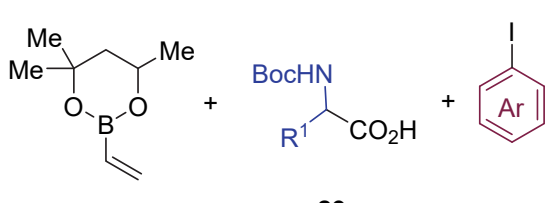

28<smiles>CC(C)O[C@H](CC1CCCN1C(=O)O)c1ccc(F)cc1</smiles>

30 a, $76 \%$
29<smiles>CC1CC(C)(C)OB(C(CC([PH2+])NC(=O)OCc2ccccc2)c2ccc(F)cc2)O1</smiles>

30b, $50 \%$

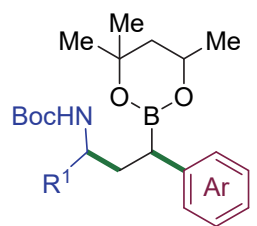

$30,33 \% \sim 79 \%$ yield

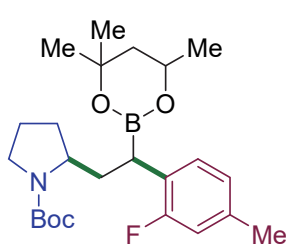

$30 \mathrm{c}, 42 \%$

图式 10 光镍催化乙烯基硼酸酯脱羧烷基芳基化反应

Scheme 10 Decarboxylative alkylarylation of vinyl boronic esters via dual nickel/photoredox catalysis

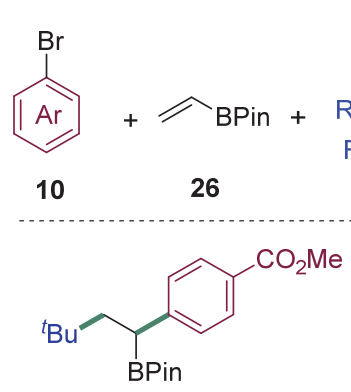

$32 \mathrm{a}, 73 \%$
4 CzIPN $(5 \mathrm{~mol} \%)$

$\mathrm{NiCl}_{2} \cdot \mathrm{DME}(7.5 \mathrm{~mol} \%)$

2,2'-Bipyridine $(7.5 \mathrm{~mol} \%)$

TMEDA, MeCN

Blue LEDs, $20 \mathrm{~h}$

31

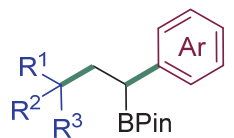

$32,45 \% \sim 81 \%$ yield

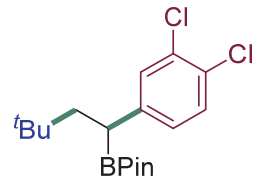

32b, $81 \%$<smiles>COC(=O)c1ccc(C(CC2(C)CCC(c3ccccc3)CC2)c2ccccc2)cc1</smiles>

32c, $51 \%$

图式 11 光镍催化乙烯基硼酸酯还原双碳官能化反应

Scheme 11 Reductive dicarbofunctionalization of vinyl boronates via dual nickel/photoredox reductive catalysis 


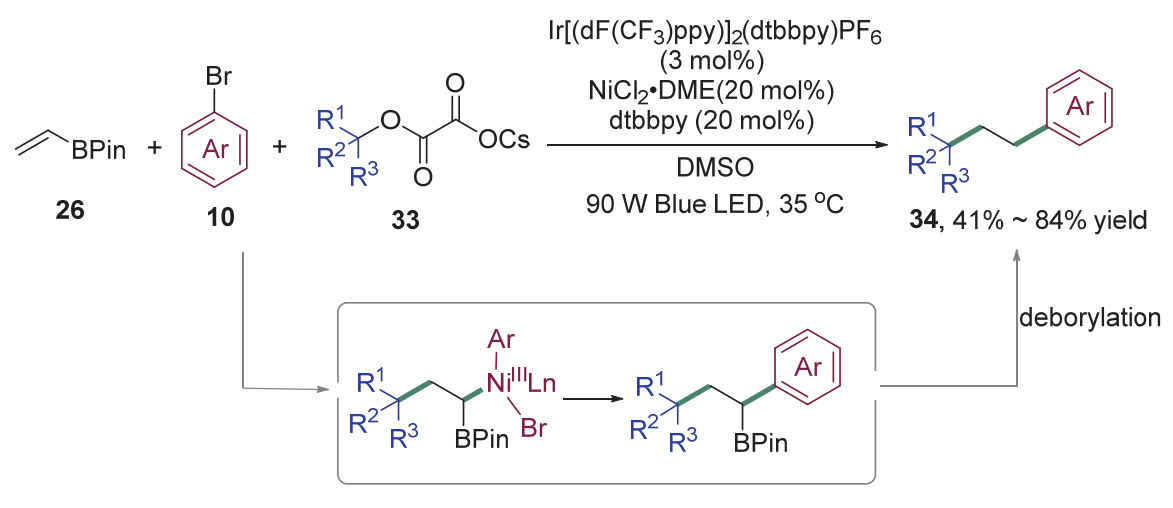

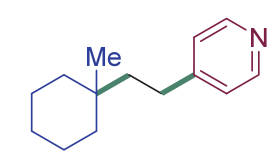

$34 a, 84 \%$<smiles>CC1(C)CCC(C)(CCc2ccncc2)CC1</smiles>

$34 d, 75 \%$<smiles>CC1(CCc2cc(C(F)(F)F)ccn2)CCCCC1</smiles>

$34 b, 68 \%$<smiles>CC1(CCc2ccncc2)CCCC1</smiles>

$34 \mathrm{e}, 45 \%$<smiles>COc1ccc(CCC2(C)CCCCC2)cc1</smiles>

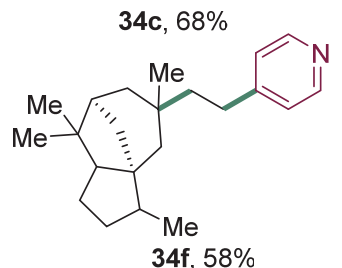

图式 12 光镍催化乙烯喼酸酯双碳偶联一脱硼串联反应

Scheme 12 Sequential alkylarylation and deborylation of vinyl boronates via dual nickel/photoredox catalysis

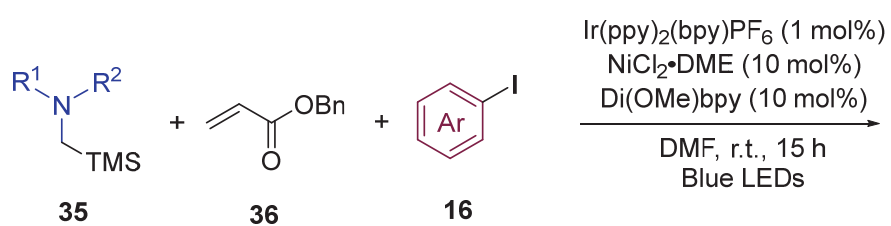

16<smiles>O=C(OCc1ccccc1)C(CCN1CCOCC1)c1ccccc1</smiles><smiles>[R]N([R])CCC(C(=O)OCC)c1ccccc1</smiles>

$37,20 \% \sim 90 \%$ yield<smiles>O=C(OCCCCCN1CCCCC1)c1ccccc1</smiles>

$37 a, 77 \%$<smiles>CCCCN(CCCC)CCC(C#N)c1ccccc1</smiles>

$37 d, 80 \%$
$37 \mathrm{~b}, 88 \%$

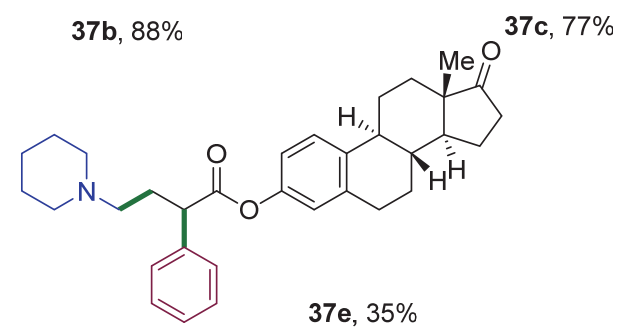

$37 e, 35 \%$

图式 13 光镍催化烯烃 1,2-芳基-氨基烷基化反应

Scheme 13 1,2-Aryl-aminoalkylation of alkenes via dual nickel/photoredox catalysis

成功兼容一级 $\alpha$-氨基烷基自由基, 以优秀的化学、区域 选择性得到高附加值的 $\gamma$-氨基酯化合物. 除了丙烯酸酯 外, 丙烯酰胺、 $\alpha, \beta$-不饱和酮及丙烯腈等缺电子烯烃也 可以有效参与反应. 该反应中, 烷基胺与激发态光催化 剂发生单电子氧化并脱除 $\beta$-硅基, 即可生成关键的 $\alpha$-氨 基烷基自由基. 实验表明, $\alpha$-硅基烷基胺的使用对该三
组分反应的成功起着关键作用，其他一级烷基自由基前 体均不能有效参与反应.

上述可见光/镍协同催化多组分反应中，自由基前 体都是预先官能团化底物. 近些年来, 基于氢原子转移 (HAT) 策略, 众多课题组利用可见光催化实现了温和条 件下烷基碳氢键的直接转化反应 ${ }^{[1-52]} .2021$ 年, 孔望清 
课题组 ${ }^{[53]}$ 利用可见光/镍协同催化烯烃、饱和烷烃和芳 基卤化物三组分 1,2-烷基芳基化反应(Scheme 14). 该反 应利用四丁基十聚铇酸铵盐(TBADT)作为光催化剂和 氢原子转移催化剂, 经光照激发后选择性活化脂肪烃 $\mathrm{C}-\mathrm{H}$ 键, 生成烷基自由基前体参与后续串联反应, 避 免了预先制备官能团化的烷基自由基前体. 环状、链状 以及杂原子取代的三级、二级、甚至一级的烷烃均能较 好地适用于该反应. 作者也进一步将该体系推广到复杂 生物活性分子的后期修饰和合成中.

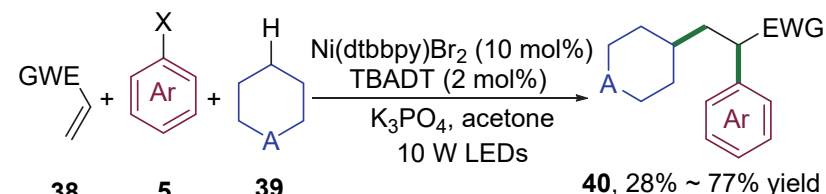

$\begin{array}{llll}38 & 5 & 39 & 40,28 \% \sim 77 \% \text { yield }\end{array}$

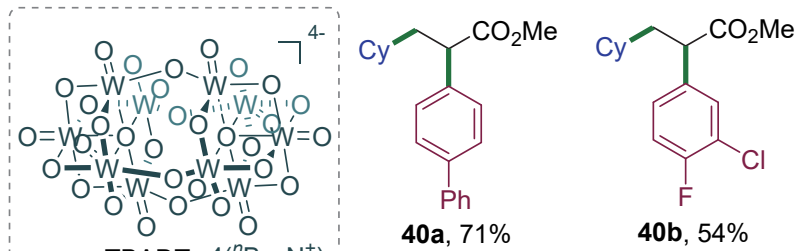

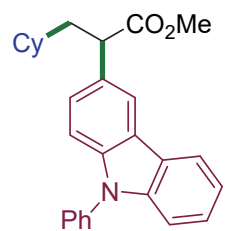

40c, $70 \%$

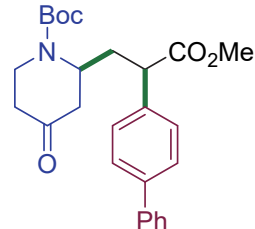

$40 d, 66 \%$

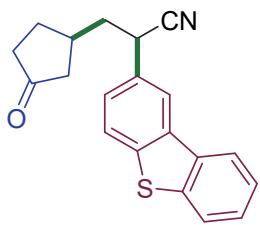

40 e, $58 \%$
图式 14 光镍催化烯烃烷基芳基化反应

Scheme 14 Alkylalkylation reaction of alkenes via dual nickel/photoredox catalysis

2021 年, Molander 等 ${ }^{[54]}$ 利用二芳基酮作为光敏剂, $\mathrm{Ni}$ (dtbbpy) $\mathrm{Br}_{2}$ 作为镍催化剂, 实现了可见光/镍协同催 化烯烃与烷烃、芳基溴的三组分烷基芳基化反应 (Scheme 15). 与 Kong 等[53]催化体系不同, 该反应利用 激发态二芳基酮作为高效的氢原子转移(HAT)试剂, 选 择性活化相应的烷基 $\mathrm{C}-\mathrm{H}$ 键; 篗氢后生成的酮基自由 基与 $\mathrm{Ni}(\mathrm{I})$ 发生单电子转移生成 $\mathrm{Ni}(0)$ 和基态二芳基酮, 完成催化循环. 该反应具有优秀的官能团兼容性和底物 适用性，一系列醚、硫醚、醇、烷基胺、烷基酰胺及烷 基硼酯的 $\mathrm{C}-\mathrm{H}$ 键均可选择性活化，生成相应的烷基自 由基, 与各类缺电子烯烃和(杂)芳基溴发生自由基加成 及芳基交叉偶联的串联反应. 机理实验和 DFT 计算结 果整体上支持光镍调控的自由基加成-芳基偶联的串联 过程, 同时作者认为氢键的存在促进了烷基自由基(如 醇)与烯烃的选择性加成过程.
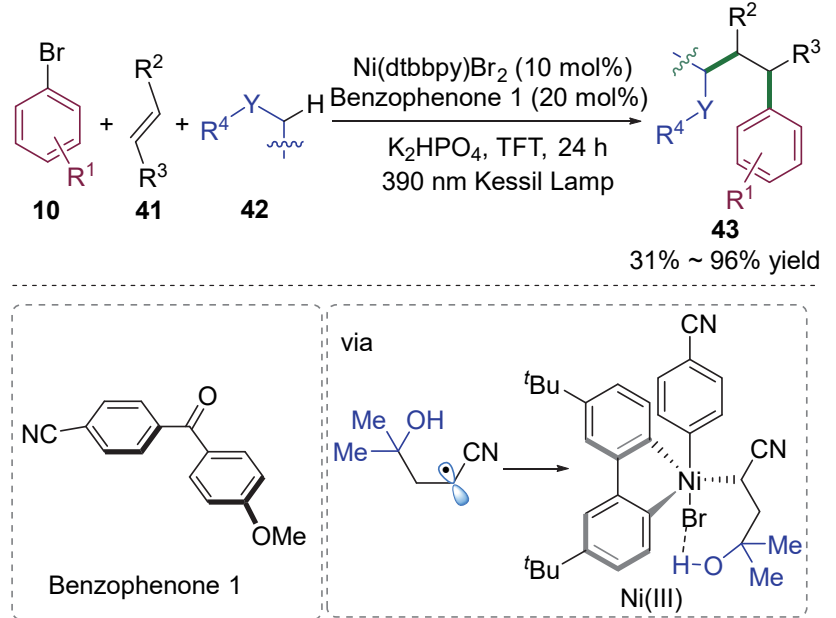<smiles>COC1(CC(C(=O)OC(C)(C)C)c2ccccc2)CCCC1</smiles>

43a, $69 \%$<smiles>CCOC(=O)C(CC1(OC)CCCC1)C(C)(C)C</smiles>

43b, $65 \%$<smiles>CCCCCCCCCCC(C)(C)O</smiles><smiles>CCC(C)OC(=O)C(CC1(O)CCC1)c1ccc(C#N)cc1</smiles>

43d, $91 \%$<smiles>COC1(CC(C#N)c2ccc(C#N)cc2)CCCC1</smiles>

$43 e, 80 \%$

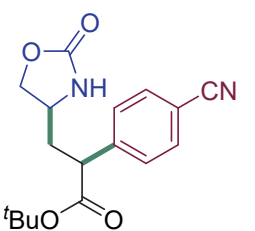

43f, $40 \%, d r=1.1: 1$
图式 15 光镍催化烯烃烷基芳基化反应

Scheme 15 Alkylalkylation reaction of alkenes via dual nickel/photoredox catalysis

\subsection{2 烯烃三组分杂原子官能团化反应}

杂原子自由基呈现出亲电特性 ${ }^{[55]}$, 易与富电子烯 烃发生自由基加成反应. 2019 年, Nevado 等 ${ }^{[45]}$ 在其报道 的光镍协同催化烯烃烷基芳基反应中，也利用亚磺酸钠 盐作自由基前体，实现了缺电子烯烃与芳基碘化物的 1,2-砜基芳基化反应(Scheme 16).

2020 年, Rueping 等 ${ }^{[56]}$ 利用磺酸钠盐为自由基前体, 芳基卤代物为偶联子，报道了光/镍协同催化的 1,6-二烯 级联交叉偶联反应，以较高的收率和非对映选择性得到 相应的五元碳环化合物(Scheme 17). 该反应历经自由 基加成/5-exo 环化/芳基偶联的串联过程，一步构建两个 新的 $\mathrm{C}-\mathrm{C}$ 键和一个 $\mathrm{C}-\mathrm{S}$ 键. 反应具有良好的底物适用 性和官能团兼容性，一系列 1,6-二烯、(杂)芳基卤化物以 及芳基和烷基亚硫酸钠等底物均能很好地适用.

2020 年，胡喜乐等 ${ }^{[57]}$ 报道了以可见光/镍协同催化 丙烯酸酯与硅烷、芳基卤化物的三组分 1,2-硅基芳基化 反应，构建了一系列重要的 $\alpha$-硅基取代羰基类化合物 (Scheme 18). 该反应以 $\operatorname{Ir}(\mathrm{dF}-\mathrm{Me}-\mathrm{ppy})_{2}(\mathrm{dtbbpy})\left(\mathrm{PF}_{6}\right)$ 为光 


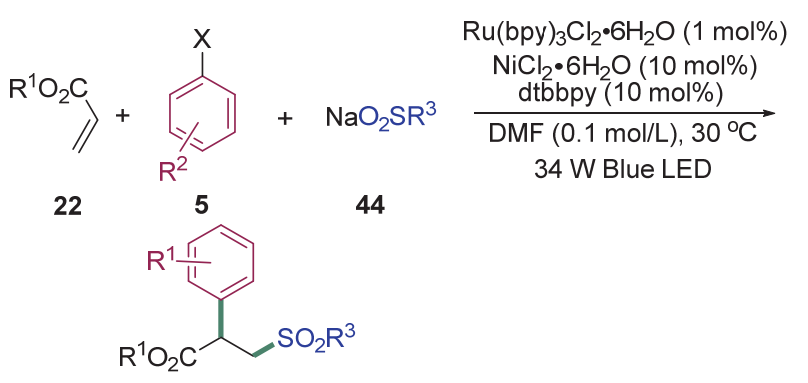

$45,27 \% \sim 69 \%$ yield

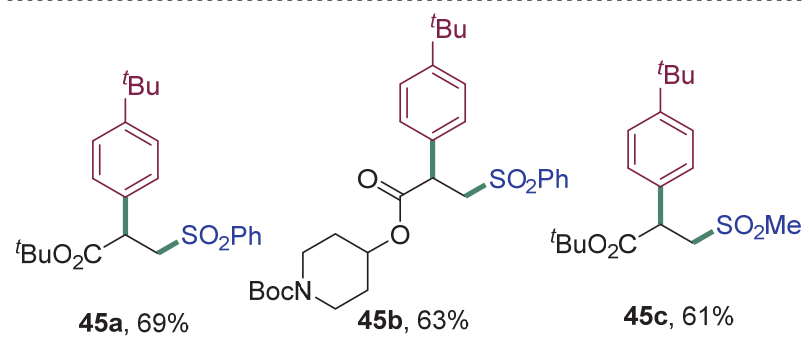

图式 16 光镍催化烯烃砜基芳基化反应

Scheme 16 Sulfonylalkylation alkylation reaction of alkenes via dual nickel/photoredox catalysis

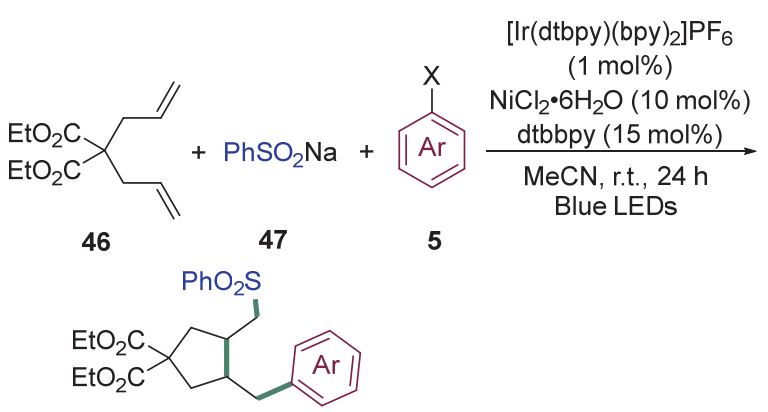

$48,58 \% \sim 99 \%$ yield

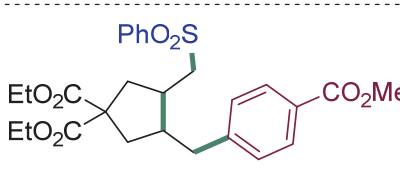

48a, $88 \%, d r=88: 12$

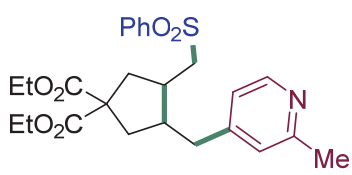

48c, $85 \%, d r=90: 10$

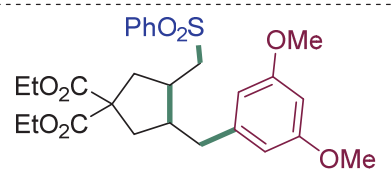

48b, $88 \%, d r=86: 14$

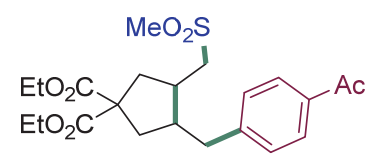

48d, $98 \%, d r=85: 15$
图式 17 光镍协同催化二烯级联交叉偶联反应

Scheme 17 Photoredox and nickel dual catalyzed cascade cross-coupling of dienes

催化剂, $\mathrm{Ni}(\operatorname{cod})_{2}$ 为镍催化剂, 反应条件温和, 官能团兼 容性良好, 为复杂硅烷的快速合成提供了高效的方法. 机理研究表明, $\mathrm{Ni}(0)$ 与芳基溴氧化加成后的 $\mathrm{Ar}-\mathrm{Ni}(\mathrm{II})-$ $\mathrm{Br}$ 物种与激发态光催化剂发生单电子转移释放 $\mathrm{Br}$ 自由 基启动反应, 该 $\mathrm{Br}$ 自由基与硅烷发生氢原子转移得到 硅基自由基. 亲核性硅基自由基与缺电子烯烃发生自由
基加成进而被镍捕获，与芳基溴进一步发生交叉偶联.

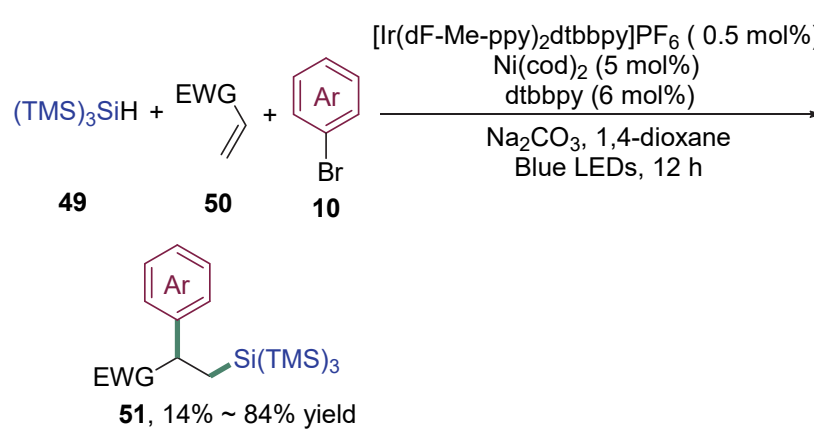<smiles>CC(=O)C(C[SiH2]C(C)(C)C)c1ccccc1</smiles>

51a, $80 \%$<smiles>COC(=O)C(C[SiH2]C(C)C)c1ccc2ncn(C)c2c1</smiles>

51c, $46 \%$<smiles>CC(=O)c1ccc(C(C#N)C[AlH2]C(C)(C)C)cc1</smiles>

51d, $84 \%$<smiles>CCOC(=O)OC(=O)C(C[SiH2]C(C)C)c1ccc(C(C)=O)cc1</smiles>

51e, $71 \%$

图式 18 光镍协同催化烯烃碳硅化反应

Scheme 18 Carbosiylation of alkenes via dual nickel/ photoredox catalysis

2021 年, Studer 等 ${ }^{[58]}$ 利用 $\alpha$-氨基-羟基酸为自由基 前体, 以 $4 \mathrm{CzIPN}$ 为光催化剂, $\mathrm{Ni}(\mathrm{dtbbpy}) \mathrm{Br}_{2}$ 为镍催化 剂, 实现了光/镍协同催化 $\alpha$-杂原子烯烃、芳基卤化物和 $\alpha$-基-羟基酸的三组分 1,2-氨基芳基化反应(Scheme 19). 反应中 $\alpha$-氨基羟基酸在碱的参与下与激发态光催化剂 发生单电子转移得到羧基自由基, 脱除一分子 $\mathrm{CO}_{2}$ 和一 分子丙酮后生成亲电性的氨基自由基, 氨基自由基与富 电子烯烃发生自由基加成生成烷基自由基，进而在镍作 用下与芳基溴发生交叉偶联得到三组分串联产物. 该反 应中自由基极性匹配效应保证了多组分反应的效率与 选择性. 该反应条件温和, 具有较好的官能团耐受性和 广泛的底物范围, 一系列 $\alpha$-氧杂、氮杂及硫杂等富电子 烯烃均能发生高效转化, 各类芳基溴、杂环芳基溴也能 很好地兼容. 此外, 该反应也能进一步拓展至酰氯偶联 子, 构建 $\beta$-氨基羰基类化合物.

\section{3 烯烃不对称双官能团化反应}

尽管在可见光/镍协同催化烯烃分子间双官能化方 
面取得了令人振奋的进展, 但由于高活性自由基物种和 光激发态物种的参与, 如何控制此类转化的立体选择性 仍面临巨大挑战.

2020 年, 储玲玲和 Gutierrez 等 ${ }^{[59]}$ 报道了可见光/镍 协同催化烯烃、烷基三氟喼酸钾和芳基溴的不对称三组 分烷基芳基化反应(Scheme 20). 该不对称反应以 $\operatorname{Ir}[\mathrm{dF}-$
$\left(\mathrm{CF}_{3}\right)$ ppy $]_{2}(\mathrm{bpy})\left(\mathrm{PF}_{6}\right), \mathrm{NiCl}_{2}(\mathrm{Py})_{4}$ 和 $(S, S)-s e c-\mathrm{BiOx}$ 作为 催化剂组合，反应条件温和，可以耐受各种不同的芳基 溴、杂环芳基溴、仲碳和叔碳烷基三氟硼酸盐，以优异 的产率和 $e e$ 值构建 $\alpha$-芳基羰基类化合物，为该类广泛 存在于许多药物分子中的手性结构单元提供了温和高 效的构建方法. 该体系可以进一步拓展到其他的缺电

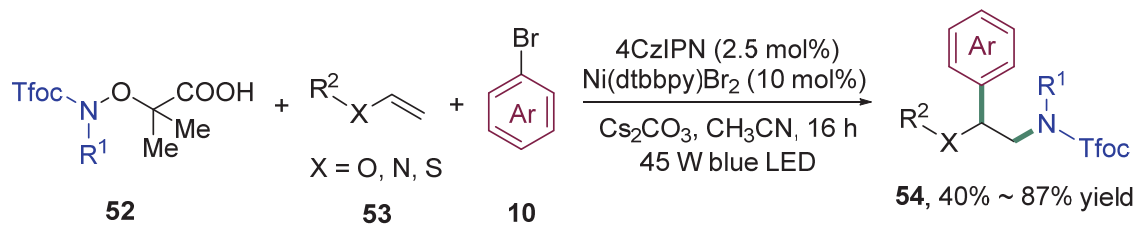<smiles>CCOC(CN(C)C(C)C)c1ccc(C(C)=O)cc1</smiles>

$54 a, 87 \%$<smiles>CCOC(CN(C)C)c1ccc(C(C)=O)cc1</smiles>

$54 c, 53 \%$<smiles>CC(=O)c1ccc(C(CC2CC2)CN(CC(C)(C)C)C(C)(C)C)cc1</smiles>

54d, $79 \%$<smiles>CC(=O)c1ccc(C(CN(C)C)OC2CC(C)CCC2C(C)C)cc1</smiles>

$54 \mathrm{e}, 79 \%, d r=1.2: 1$<smiles>[M]C(CC(=O)OC)OC(CN(C)C)c1ccc(C(C)=O)cc1</smiles>

$\mathbf{5 4 f}, 85 \%, d r=1: 1$

图式 19 光镍催化烯烃胺化芳基化反应

Scheme 19 Aminoarylation of alkenes via dual nickel/ photoredox catalysis

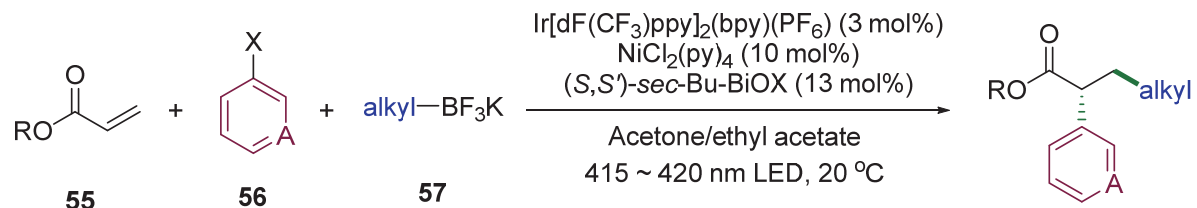

55

56

57

$\mathbf{5 8}, 53 \% \sim 91 \%$ yield $15 \% \sim 95 \%$ ee
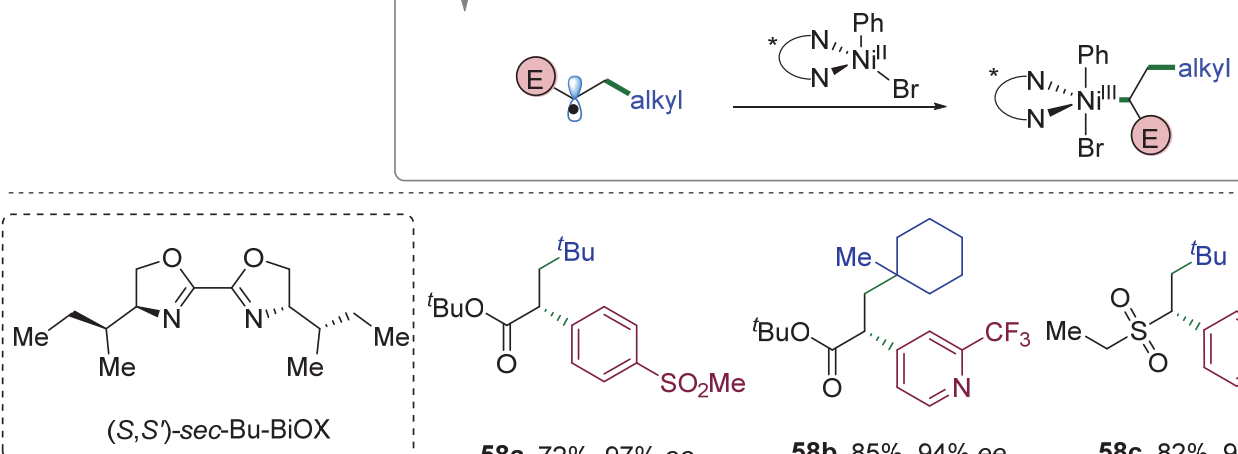<smiles>CO[SH](=O)(OC)c1ccc(C(CC(C)C)C(=O)OC(C)(C)C)cc1</smiles>

58a, $72 \%, 97 \%$ ee<smiles>CCCCOC(=O)C(CC1(C)CCCCC1)c1ccnc(C(F)(F)F)c1</smiles>

58b, $85 \%, 94 \%$ ee<smiles>CCS(=O)(=O)[C@H](CC(C)C)c1ccnc(C(F)(F)F)c1</smiles>

$58 c, 82 \%, 90 \%$ ee<smiles>CC(C)(C)OC(=O)[C@H](CC1CC2CCC1C2)c1ccnc(C(F)(F)F)c1</smiles>

58d, $67 \%, 95 \%$ ee, $d r=1: 1$<smiles>COC(=O)C(CC1CCCC1)c1ccc(S(C)(=O)=O)c(Cl)c1</smiles>

$58 e, 82 \%, 90 \%$ ee (i) TFA, DCM (ii) $(\mathrm{COCl})_{2}$ $\left[\mathrm{N}_{\mathrm{N}}^{\mathrm{N}}\right]^{\mathrm{NH}_{2}}$<smiles>O=C(Nc1cnccn1)C(CC1CCCC1)c1ccc(F)c(I)c1</smiles>

58f, $62 \%, 92 \%$ ee

This route: 3 steps Preious routes: 8 steps

图式 20 光镍催化烯烃不对称烷基芳基化反应

Scheme 20 Asymmetric alkylalkylation of alkenes via dual nickel/photoredox catalysis 
子烯烃, 如丙烯酰胺、乙烯基砜和乙烯基膦酸酯等, 以 及杂原子取代烯烃如乙烯基胺和乙烯基醚等, 但是 $e e$ 值有不同程度的降低. 为了探索该方法的合成应用价 值，作者利用该反应从简单的烯烃原料出发快速合成了 $(R)$-氟比洛芬类似物和 $(R)$-吡格列汀先导化合物. 机理 实验和 DFT 计算表明, 该反应经历自由基串联过程: 烷 基自由基与丙烯酸酯发生自由基加成生成 $\alpha$-羰基自由 基，其被激发态四面体* $\mathrm{Ar}-\mathrm{Ni}$ (II)捕获得到高价镍物种, 随后快速还原消除构建 1,2-烷基芳基化产物. 在该过程 中, $\alpha$-羰基自由基与四面体* $\mathrm{Ar}-\mathrm{Ni}(\mathrm{II})$ 的加成步骤为该反 应的立体选择性决定步骤. 同时, 共价相互作用(NCI) 分析表明, 缺电性芳环与羰基等基团间非共价相互作用 提高了该反应的对映选择性.

2020 年, 王川课题组等 ${ }^{[60]}$ 报道了可见光/镍协同催 化邻位氨基甲酰氯芳基烯烃和醛的不对称酰基氨基甲 酰化反应, 高对映选择性地合成了一系列 3,3-二取代吲 哚化合物(Scheme 21). 该反应结合光促氢原子转移和 单电子转移, 以四丁基十铇酸铵 (TBADT)为光催化剂, $\mathrm{Ni}(\mathrm{OTf})_{2}$ 为镍催化剂, 手性 PHOX 为优势配体, 为手性 四元立体中心的吗哚化合物的构建提供了高效方法. 反 应条件温和, 官能团兼容性好, 各类脂肪醛和芳香醛都 能很好地适用. 反应可能的机理路线如下: 激发态 *TBADT 与醛发生氢原子转移形成酰基自由基, $\mathrm{Ni}(0)$ 捕 获该自由基生成酰基镍物种; 酰基镍与氨基甲酰氯发生 氧化加成, 并与烯烃迁移插入得到(酰基)(烷基) Ni(III)物 种, 快速还原消除构建目标化合物. 根据初步的机理研 究, 作者推断镍介导烯烃分子内迁移插入为该反应的立 体选择性决定步骤.

\section{2 可见光/镍协同催化炔烃双官能团化反应}

多取代烯烃是一类广泛存在于药物、农用化学品和 活性天然产物中的结构单元 ${ }^{[6]}$. 过渡金属催化炔烃双 官能化是构建多取代烯烃的一类高效方法, 在合成中有 着重要的应用 ${ }^{[62-63]}$. 近年来, 自由基介导炔烃双官能团 化反应也受到了广泛的关注与发展, 为多取代烯烃的高 效构建提供了一种温和、选择性互补的策略 ${ }^{[64]}$. 该反应 类型历经炔烃自由基加成生成烯基自由基, 烯基自由基 被金属物种捕获并发生交叉偶联串联反应, 反应的立体 选择性取决于烯基自由基与金属物种的捕获过程，一般 都是得到反式加成的产物 ${ }^{[65]}$.

2018 年, 储玲玲等 ${ }^{[66]}$ 以 $\operatorname{Ir}\left[\mathrm{dF}\left(\mathrm{CF}_{3}\right) \mathrm{ppy}\right]_{2}(\mathrm{dtbbpy}) \bullet$ $\mathrm{PF}_{6}$ 为光催化剂, $\mathrm{NiCl}_{2} \cdot \mathrm{DME}$ 为镍催化剂, $\mathrm{dtbbpy}$ 为配体, 实现了首例可见光/镍协同催化炔烃、叔醇草酸铯盐和芳 基卤代物的三组分烷基芳基化反应，以顺式立体选择性 构建了一系列三取代烯烃化合物(Scheme 22). 该反应

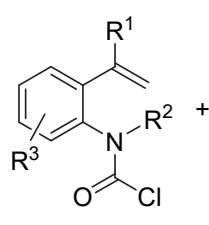

59

60
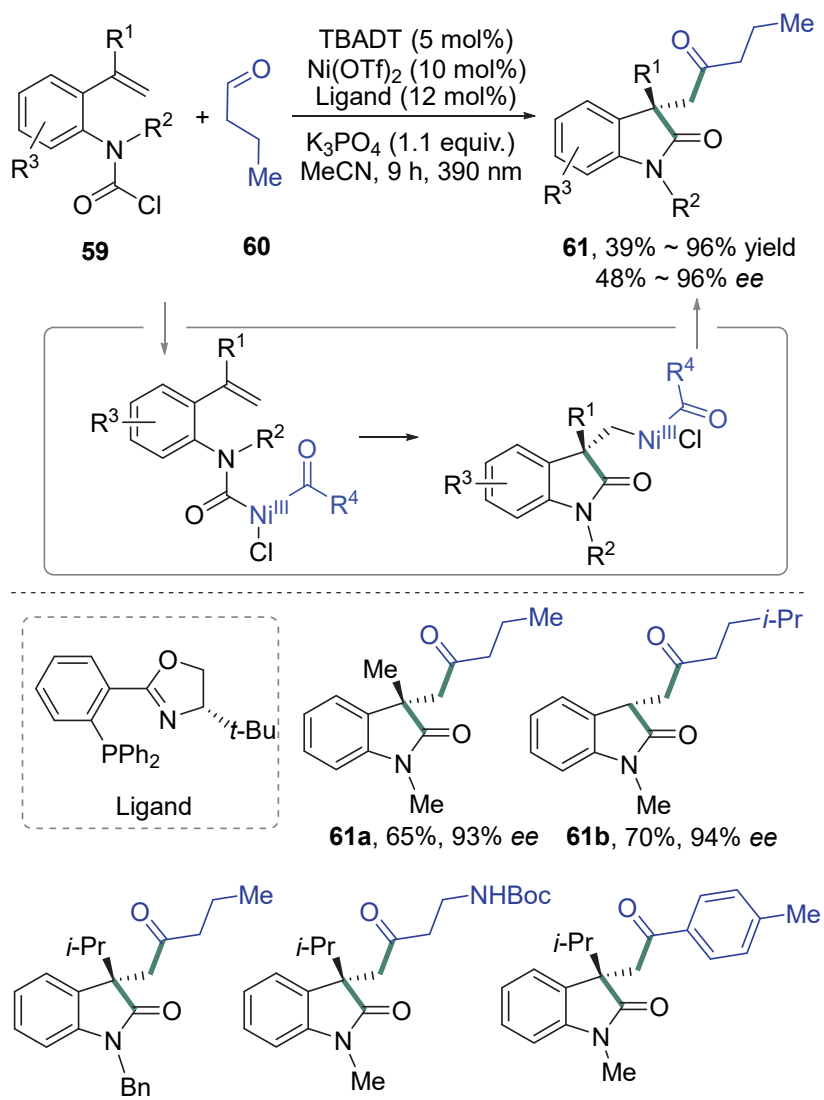

61c, $46 \%, 92 \%$ ee $\quad 61 d, 96 \%, 95 \%$ ee $\quad 61 e, 53 \%, 94 \%$ ee

图式 21 光镍催化烯烃不对称酰基氨基甲酰化反应 Scheme 21 Asymmetric acyl-carbamoylation of alkenes via dual nickel/photoredox catalysis

条件温和, 官能团兼容性好, 底物适用性广, 立体选择 性优秀. 机理研究表明, 该反应经过单电子转移 (SET) 和三线态-三线态能量转移(EnT)的串联过程. 首先, 光/ 镍调控单电子转移促进自由基加成/芳基交叉偶联等串 联, 构建多个化学键, 生成相应的反式烯烃产物. 接着, 反式烯烃自身作为光敏剂, 在光激发下发生能量转移进 而发生 $E \rightarrow Z$ 异构化, 得到热力学不稳定的顺式烯烃产 物.

随后，储玲玲等 ${ }^{[67]}$ 利用烯基自由基易发生分子内 1,5-氢原子转的特性 ${ }^{[64]}$, 实现了可见光/镍协同催化烷基 炔烃、环状叔醇铯盐和芳基卤化物的三组分串联反应， 构建了 1,3-双取代的环状烷烃化合物(Scheme 23). 该串 联过程历经环烷基自由基与烷基炔烃的选择性加成、烯 基自由基分子内 1,5 -氢迁移生成仲碳烷基自由基以及镍 调控芳基交叉偶联等步骤，为构建多取代环烷烃等复杂 结构单元提供了新颖、有效的合成方法. 五元/六元的碳 环、氧杂环等环醇叔醇均能高效、高区域选择性发生转 化，反应效率受环上的取代基位阻效应影响较大．链 状、四元及七元环叔醇衍生物目前不适用, 作者据此推 断, 烯基自由基分子内 1,5 -氢迁移的效率受构象影响. 


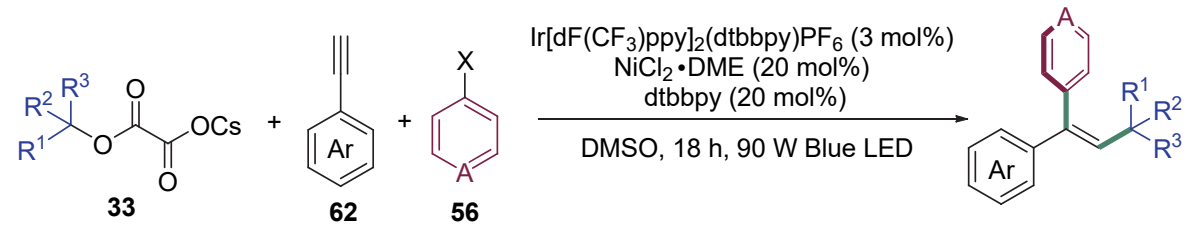

63, $52 \% \sim 91 \%$ yield $Z: E$ up to $97: 3$

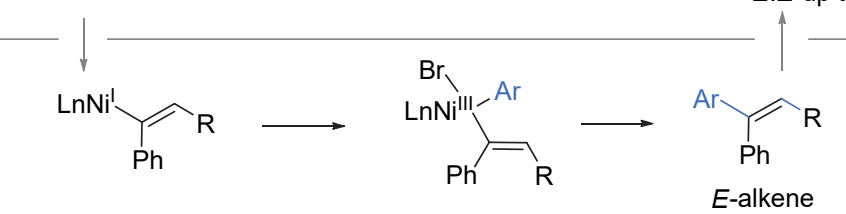

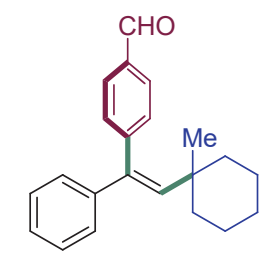

63a, $83 \%, Z: E=96: 4$<smiles>[M]C1(C=C(c2ccc(C(C)=O)cc2)c2ccc(C(C)(C)C)cc2)CCCCC1</smiles>

63d, $75 \%, Z: E=88: 12$<smiles>CC1(C)CCC(C)(C=C(c2ccc(C=O)cc2)c2ccc(C(C)(C)C)cc2)CC1</smiles>

63b, $83 \%, Z: E=95: 5$<smiles>CC(C)(C)c1ccc(/C(=C\C2(C)CCCCC2(C)C)c2ccc(C(=O)O)cc2)cc1</smiles>

63e, $75 \%, Z: E=84: 16$<smiles>[M]C1(C=C(c2ccc(C(C)=O)cc2)c2ccc(C(C)(C)C)cc2)CCCCC1</smiles>

63c, $87 \%, Z: E=91: 9$<smiles>CC(C)(C)c1ccc(C(=CC2(C)CCCCC2(C)C)c2nc3ccccc3s2)cc1</smiles>

63f, $63 \%, Z: E=97: 3$

图式 22 光镍催化炔烃顺式烷基芳基化反应

Scheme 22 syn-Alkylarylation of alkynes via dual nickel/photoredox catalysis

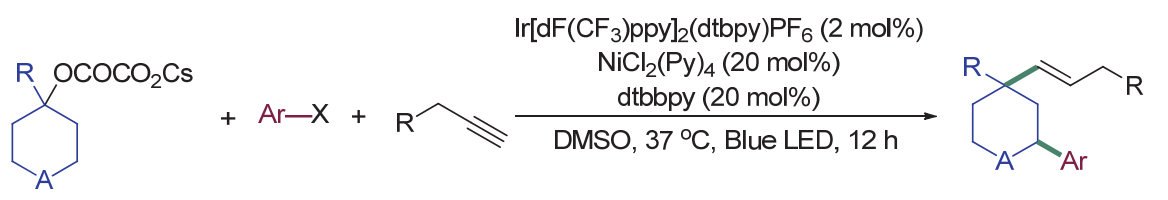

64

5

65

$66,40 \% \sim 76 \%$ yield dr 1:1 1:1.2
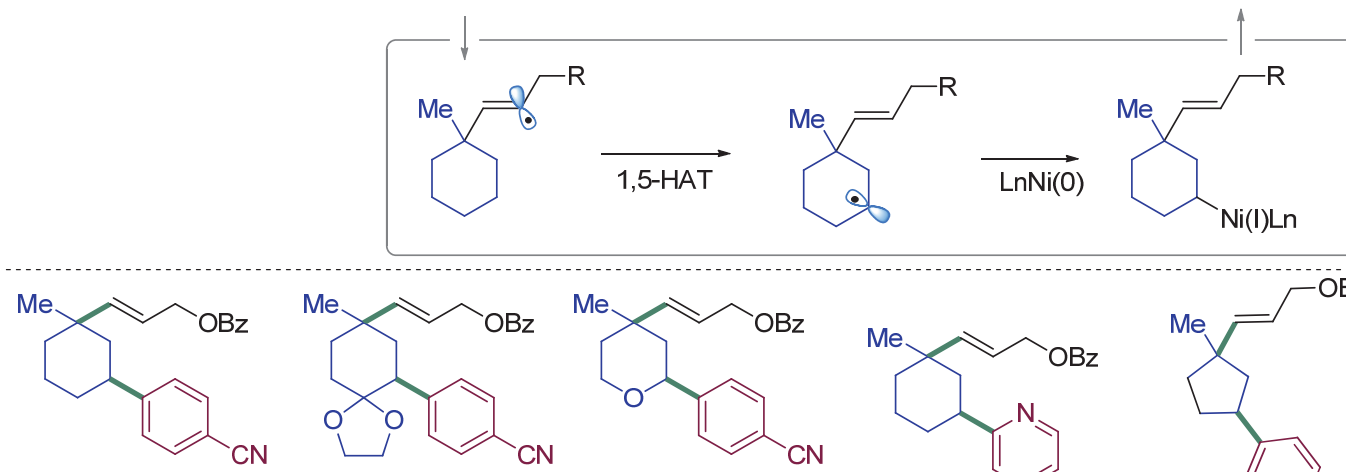<smiles>CC1(C=CCOC(C)(C)C)CCOC(c2ccc(C#N)cc2)C1</smiles><smiles>CCCCOCC=CC1(C)CCCC(c2ccccn2)C1</smiles>

66d, $77 \%$

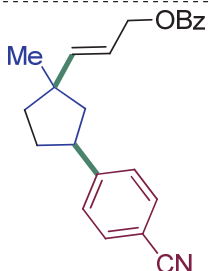

$66 e, 40 \%$

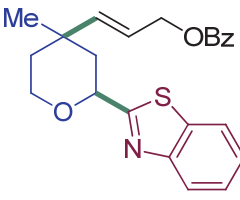

$66 f, 56 \%$

图式 23 镍催化草酸铯盐的串联反应

Scheme 23 Radical cascade reaction of cyclic oxalates via photoredox/nickel catalysis 
2019 年, Rueping 等[68]报道了可见光与镍协同催化 的炔烃、芳基卤化物及亚磺酸钠的三组分交叉偶联反应, 一锅法构建了多取代烯基亚砜化合物(Scheme 24). 该 反应兼容各类末端炔烃、芳基溴化物以及芳基/烷基亚磺 酸钠, 具有出色的化学选择性、区域选择性和立体选择 性. 值得指出的是, 该反应可以通过调控具有合适三重 态能量的光催化剂, 立体发散性地构建顺、反式三取代 烯烃. 以 $\left[\mathrm{Ru}(\mathrm{bpy})(\mathrm{dtbbpy})_{2}\right]\left(\mathrm{PF}_{6}\right)_{2}$ 为光催化剂得到反式 加成的烯基砜产物; 而以 $\operatorname{Ir}\left({ }^{t} \mathrm{Bu}-\mathrm{ppy}\right)_{2}(\mathrm{dtbbpy})\left(\mathrm{PF}_{6}\right)$ 为光 催化剂时则得到顺式加成烯基砜产物. 机理研究表明, $\mathrm{Ru}$-基光催化剂与镍发生单电子转移; 而 $\mathrm{Ir}$-基光催化剂 具有合适的三线态能量，与镍发生单电子转移的同时, 还可以与烯烃产物发生能量转移, 从而生成热力学较为 不稳定的顺式烯烃.
2020 年, Rueping 等 ${ }^{69}$ 将该体系进一步推广, 以氨 基酸为自由基前体，报道了可见光/镍协同催化炔烃三 组分烷基芳基化反应，以良好收率得到三取代的烯烃产 物(Scheme 25). 在碱的作用下, 激发态光催化剂氧化 $\alpha$ 氨基酸并脱除一分子 $\mathrm{CO}_{2}$ 后释放烷基自由基，进而启动 该串联反应. 该反应条件温和, 具有较好的底物适用性 和官能团耐受性. 该反应的立体选择性中等, 以顺式加 成三取代烯烃为主.

同烯烃分子内环化反应相比，炔烃分子内环化的串 联反应的报道较少. 2021 年, Nishibayashi 等[70]利用 4-烷 基-1,4-二氢吡啶为烷基化试剂, 实现了可见光/镍协同催 化碘代炔烃与 4-烷基-1,4-二氢吡啶的两组分环化偶联反 应，以良好到优秀的产率构建了乙烯基环戊烷化合物 (Scheme 26). 该反应以简单的 $f a c-\operatorname{Ir}[\mathrm{dF}(\mathrm{ppy})]_{3} / \mathrm{NiCl}_{2} /$
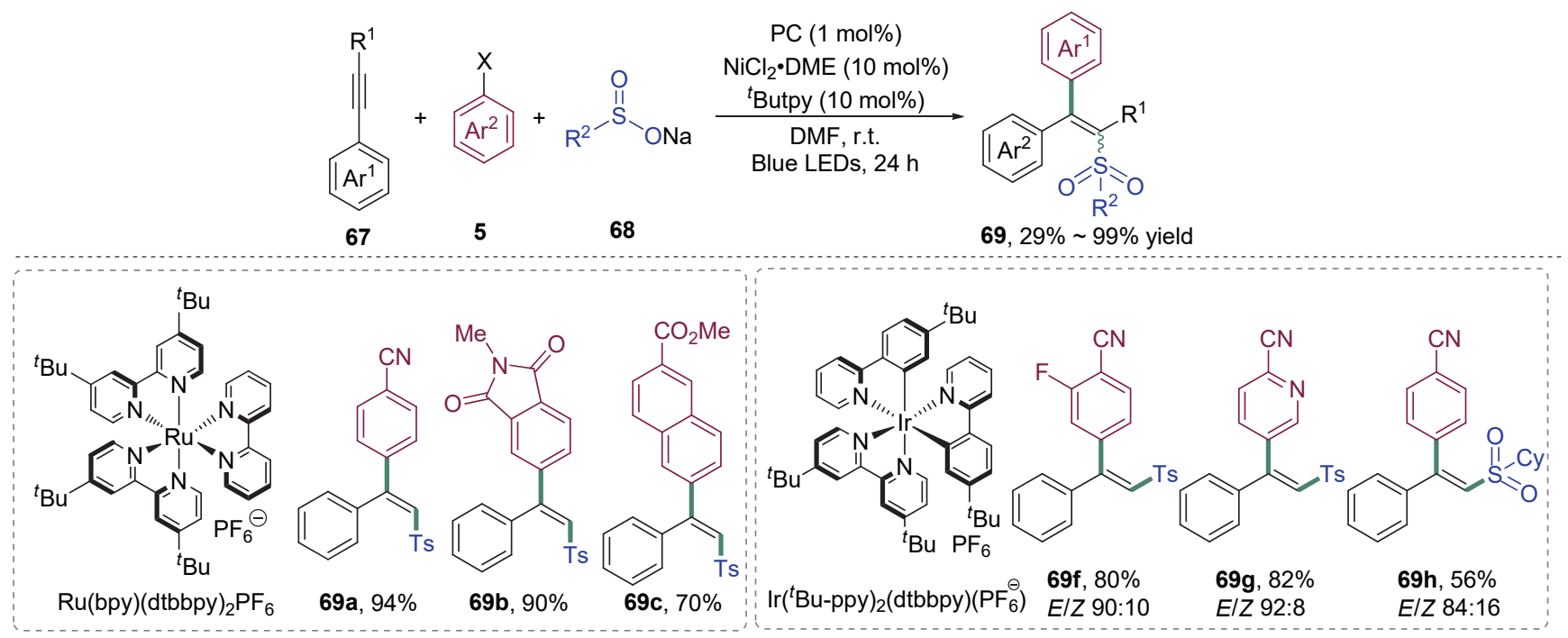

图式 24 光镍催化炔烃立体发散性砜基芳基化反应

Scheme 24 Stereodivergent sulfonylarylation of alkynes via dual nickel/photoredox catalysis

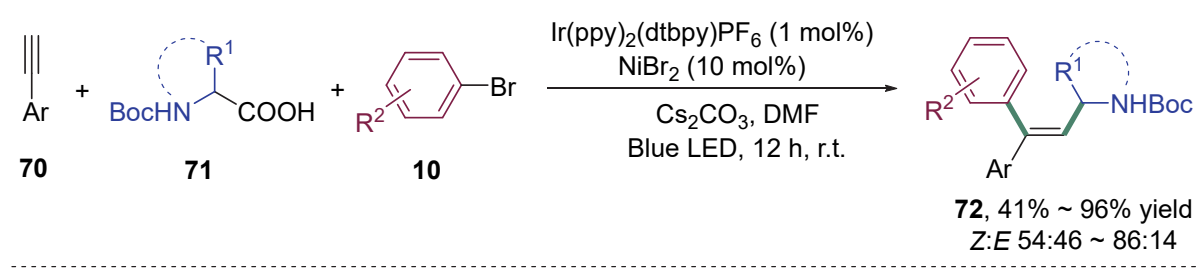

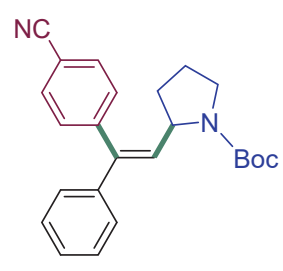

72a, 72\%, Z:E 71:29

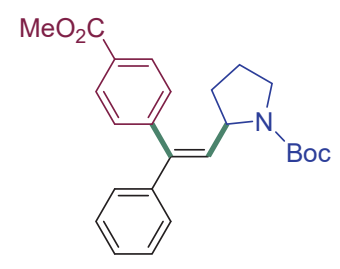

72b, $64 \%, Z: E 56: 44$

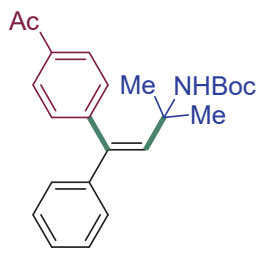

72c, $61 \%, Z: E 86: 14$

图式 25 光镍催化炔烃 1,2-烷基芳基化反应

Scheme 25 1,2-Alkylarylation of alkynes via dual nickel/photoredox catalysis 


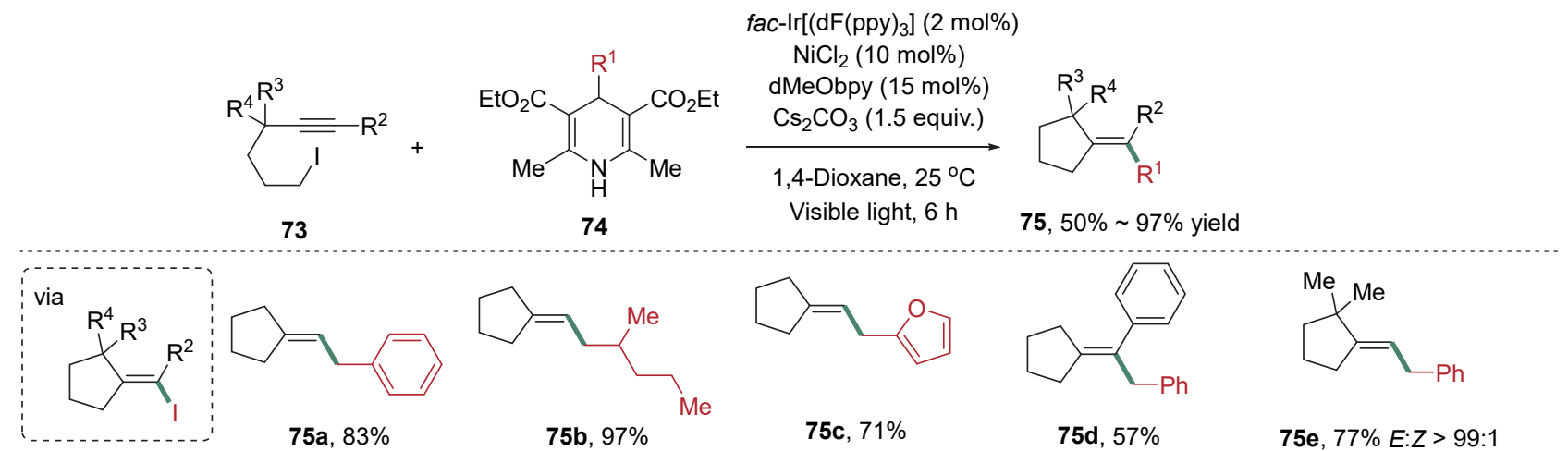

图式 26 光镍催化炔烃环化烷基化反应

Scheme 26 Alkylative cyclization of alkynes via dual nickel/photoredox catalysis

$\mathrm{d}(\mathrm{MeO})$ bpy 为催化剂组合, 反应条件温和, 兼容各类内 炔烃、末端炔烃以及(杂)芳苄基-1,4-二氢吡啶. 机理研 究表明, 光促条件下碘代炔烃发生分子内 5-exo 环化生 成的烯基碘为活性中间体, 进而在镍物种促进下与 4-烷 基-1,4-二氢吡啶发生交叉偶联得到最终产物.

2021 年, 储玲玲课题组 ${ }^{[71]}$ 利用光氧化还原与镍协 同催化策略, 实现了炔烃与芳基澳两组分 1,2-加成反应, 以优秀的区域选择性构建了重要合成砌块烯基溴化物 (Scheme 27). 该方法操作简单，反应条件温和，可广泛 适用于(杂)芳基溴、末端炔烃、内炔烃、烯炔及二炔等 底物, 所得到的烯基溴产物发生多样化合成转化. 机理 研究表明, 芳基溴与 $\mathrm{Ni}(0)$ 氧化加成生成的 $\mathrm{Ar}-\mathrm{Ni}(\mathrm{II})-\mathrm{Br}$ 物种在光促作用下释放 $\mathrm{Br}$ 自由基, 其与炔烃发生选择 性自由基加成得到烯基自由基, 后者进一步与 $\mathrm{Ar}-\mathrm{Ni}$ 发 生交叉偶联得到最终产物. 该方法为烯基卤化物的构建 提供了一种新颖、互补的合成方法.

\section{3 总结和展望}

过去的几年里，可见光/金属协同催化受到了广泛 的关注, 实现了诸多单一催化循环难以实现的挑战性转 化. 由于镍催化剂独特的单电子属性及催化偶联活性, 可见光/镍协同催化的交叉偶联反应发展最为迅速. 可 见光/镍协同催化烯烃和炔烃参与的双官能团化反应, 可以从简单的原料出发快速构建复杂结构单元, 大大提 高了合成效率. 光镍协同催化体系的发展, 不仅为该领 域拓宽了偶联子的类型与适用性，提高了官能团兼容性 和底物适用性, 同时光氧化还原体系特有的能量转移也 为该类转化带来了新颖、互补的反应活性和选择性. 尽 管如此，该领域的发展仍面临着诸多挑战. 在底物适用 性方面, 烯烃主要受限于活化烯烃, 非活化烯烃参与的 例子非常少，而分子内烯烃和分子内炔烃的反应性尚未 得到有效解决, 如何解决该类底物的区域选择性也面临 很大的挑战. 目前发展的催化体系, 多数自由基前体

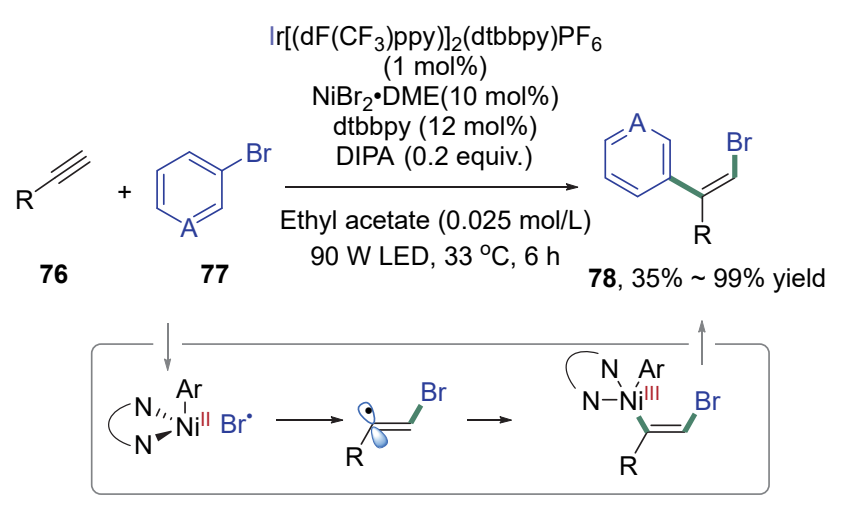<smiles>FC(F)(F)c1ccc(C(=CBr)c2cc(C(=CBr)c3ccnc(C(F)(F)F)c3)cc(C(F)(F)F)c2)cc1</smiles>

78a, 92\% Z:E 49:51 78b, 96\% Z:E 51:49 78c, 84\% Z:E 38:62<smiles>CC/C=C(\Br)C(CC)c1ccnc(C(F)(F)F)c1</smiles>

78d, 66\% Z:E 45:55 78e, 96\% Z:E 45:55 78f, 38\% Z:E 57:43

图式 27 光镍催化炔烃 1,2-溴化芳基化反应

Scheme 27 1,2-Bromoarylation of alkynes via photoredox/ nickel catalysis

都是较为稳定的叔碳及仲碳烷基试剂, 发展新型的自由 基前体，特别是一级烷基试剂和杂原子试剂仍是一大难 题. 在选择性调控方面, 光促体系涉及激发态物种和高 活性自由基，可见光/镍协同催化烯烃不对称双官能团 化反应发展仍较为缓慢. 另外, 光促能量转移可调控炔 烃双官能团化反应的立体选择性，为烯烃立体选择性合 成提供了新颖、有效的途径，但是目前该策略受限于烯 
烃产物结构, 催化剂可控的例子比较少.

总之, 在可见光/镍协同催化烯烃炔烃双官能团化

反应领域机遇与挑战并存. 我们相信, 随着可见光催化

和过渡金属催化的蓬勃发展, 可见光/过渡金属协同催 化将为烯烃、炔烃的选择性转化带来新颖、高效、高选 择性的解决策略, 为温和条件下从简单的起始原料构建 复杂结构骨架提供可以互为补充的方法.

\section{References}

[1] Tasker, S. Z.; Standley, E. A.; Jamison, T. F. Nature 2014, 509, 299.

[2] Ananikov, V. P. ACS Catal. 2015, 5, 1964.

[3] Cheng L.; Zhou, Q. Acta Chim. Sinica 2020, 78, 1017 (in Chinese). (程否, 周其林, 化学学报, 2020, 78, 1017.)

[4] Zhu, C.; Yue, H.; Jia, J.; Rueping, M. Angew. Chem., Int. Ed. 2021, $60,17810$.

[5] Fu, G. C. ACS Cent. Sci. 2017, 3, 692.

[6] Choi, J.; Fu, G. C. Science 2017, 356, 1265.

[7] Xuan, J.; Xiao, W.-J. Angew. Chem., Int. Ed. 2012, 51, 6828.

[8] Prier, C. K.; Rankic, D. A.; MacMillan, D. W. C. Chem. Rev. 2013, $113,5322$.

[9] Romero, N. A.; Nicewicz, D. A. Chem. Rev. 2016, 116, 10075.

[10] Bell, J. D.; Murphy, J. A. Chem. Soc. Rev. 2021, 50, 9540.

[11] Gui, Y.-Y.; Sun, L.; Lu, Z.-P.; Yu, D.-G. Org. Chem. Front. 2016, 3, 522.

[12] Twilton, J.; Le, C.; Zhang, P.; Shaw, M. H.; Evans, R. W.; MacMillan, D. W. C. Nat. Rev. Chem. 2017, 1, 0052.

[13] Milligan, J. A.; Phelan, J. P.; Badir, S. O.; Molander, G. A. Angew. Chem., Int. Ed. 2019, 58, 6152.

[14] Zhu, C.; Yue, H.; Chu, L.; Rueping, M. Chem. Sci. 2020, 11, 4051.

[15] Zhu, S.; Zhao, X.; Li, H.; Chu, L. Chem. Soc. Rev. 2021, 50, 10836.

[16] Plesniak, M. P.; Huang, H.-M.; Procter, D. J. Nat. Rev. Chem. 2017, $1,0077$.

[17] McDonald, R. I.; Liu, G.; Stahl, S. S. Chem. Rev. 2011, 111, 2981.

[18] Dhungana, R. K.; KC, S.; Basnet, P.; Giri, R. Chem. Rec. 2018, 18 , 1314.

[19] Giri, R.; Kc, S. J. Org. Chem. 2018, 83, 3013.

[20] Zhang, J.-S.; Liu, L.; Chen, T.; Han, L.-B. Chem.-Asian J. 2018, 13, 2277.

[21] Derosa, J.; Apolinar, O.; Kang, T.; Tran, V. T.; Engle, K. M. Chem. Sci. 2020, 11, 4287.

[22] Tu, H.-Y.; Zhu, S.; Qing, F.-L.; Chu, L. Synthesis 2020, 52, 1346.

[23] Qi, X.; Diao, T. ACS Catal. 2020, 10, 8542.

[24] Luo, Y.-C.; Xu, C.; Zhang, X. Chin. J. Chem. 2020, 38, 1371.

[25] Choi, J.; Fu, G. C. Science 2017, 356, eaaf7230.

[26] Merino, E.; Nevado, C. Chem. Soc. Rev. 2014, 43, 6598.

[27] Lin, J.; Song, R.-J.; Hu, M.; Li, J.-H. Chem. Rec. 2019, 19, 440.

[28] Wang, F.; Chen, P.; Liu, G. Acc. Chem. Res. 2018, 51, 2036.

[29] Li, Z.-L.; Fang, G.-C.; Gu, Q.-S.; Liu, X.-Y. Chem. Soc. Rev. 2020 , $49,32$.

[30] Liu, W.; Kong, W. Org. Chem. Front. 2020, 7, 3941.

[31] Diccianni, J.; Lin, Q.; Diao, T. Acc. Chem. Res. 2020, 53, 906.

[32] Ping, Y.; Kong, W. Synthesis 2020, 52, 979.

[33] Poremba, K. E.; Dibrell, S. E.; Reisman, S. E. ACS Catal. 2020, 10, 8237.

[34] Badir, S. O.; Molander, G. A. Chem 2020, 6, 1327.

[35] Yin, G.; Mu, X.; Liu, G. Acc. Chem. Res. 2016, 49, 2413.

[36] Tasker, S. Z.; Jamison, T. F. J. Am. Chem. Soc. 2015, 137, 9531.
[37] Harper, M. J.; Emmett, E. J.; Bower, J. F.; Russell, C. A. J. Am. Chem. Soc. 2017, 139, 12386.

[38] Li, J.; Luo, Y.; Cheo, H. W.; Lan, Y.; Wu, J. Chem 2019, 5, 192.

[39] Latrache, M.; Hoffmann, N. Chem. Soc. Rev. 2021, 50, 7418.

[40] Zheng, S.; Gutierrez-Bonet, A.; Molander, G. A. Chem 2019, 5, 339.

[41] Choi, G. J.; Knowles, R. R. J. Am. Chem. Soc. 2015, 137, 9226.

[42] Zheng, S.; Zhang, S.-Q.; Saeednia, B.; Zhou, J.; Anna, J. M.; Hong, X.; Molander, G. A. Chem. Sci. 2020, 11, 4131.

[43] Weires, N. A.; Slutskyy, Y.; Overman, L. E. Angew. Chem., Int. Ed. 2019, 58,8561 .

[44] Guo, L.; Tu, H. Y.; Zhu, S.; Chu, L. Org. Lett. 2019, 21, 4771.

[45] Garcia-Dominguez, A.; Mondal, R.; Nevado, C. Angew. Chem., Int Ed. 2019, 58, 12286.

[46] Campbell, M. W.; Compton, J. S.; Kelly, C. B.; Molander, G. A. J. Am. Chem. Soc. 2019, 141, 20069.

[47] Mega, R. S.; Duong, V. K.; Noble, A.; Aggarwal, V. K. Angew. Chem., Int. Ed. 2020, 59, 4375.

[48] Sun, S. Z.; Duan, Y.; Mega, R. S.; Somerville, R. J.; Martin, R. Angew. Chem., Int. Ed. 2020, 59, 4370.

[49] Feng, X.; Guo, L.; Zhu, S.; Chu, L. Synlett 2021, 32, 1519.

[50] Zheng, S.; Chen, Z.; Hu, Y.; Xi, X.; Liao, Z.; Li, W.; Yuan, W. Angew. Chem., Int. Ed. 2020, 59, 17910.

[51] Shi, L.; Xia, W. Chem. Soc. Rev. 2012, 41, 7687.

[52] Qin, Q.; Jiang, H.; Hu, Z.; Ren, D.; Yu, S. Chem. Rec. 2017, 17, 754.

[53] Xu, S.; Chen, H.; Zhou, Z.; Kong, W. Angew. Chem., Int. Ed. 2021, 60, 7405 .

[54] Campbell, M. W.; Yuan, M.; Polites, V. C.; Gutierrez, O.; Molander, G. A. J. Am. Chem. Soc. 2021, 143, 3901.

[55] Yu, X.-Y.; Zhao, Q.-Q.; Chen, J.; Xiao, W.-J.; Chen, J.-R. Acc. Chem. Res. 2020, 53, 1066 .

[56] Huang, L.; Zhu, C.; Yi, L.; Yue, H.; Kancherla, R.; Rueping, M. Angew. Chem., Int. Ed. 2020, 59, 457.

[57] Zhang, Z.; Hu, X. ACS Catal. 2020, 10, 777.

[58] Jiang, H.; Yu, X.; Daniliuc, C. G.; Studer, A. Angew. Chem., Int. Ed. 2021, 60, 14399 .

[59] Guo, L.; Yuan, M.; Zhang, Y.; Wang, F.; Zhu, S.; Gutierrez, O.; Chu, L. J. Am. Chem. Soc. 2020, 142, 20390.

[60] Fan, P.; Lan, Y.; Zhang, C.; Wang, C. J. Am. Chem. Soc. 2020, 142, 2180.

[61] Jordan, V. C. J. Med. Chem. 2003, 46, 1081.

[62] Chinchilla, R.; Nájera, C. Chem. Rev. 2014, 114, 1783.

[63] Jackson, E. P.; Malik, H. A.; Sormunen, G. J.; Baxter, R. D.; Liu, P.; Wang, H.; Shareef, A.-R.; Montgomery, J. Acc. Chem. Res. 2015, $48,1736$.

[64] Wille, U. Chem. Rev. 2013, 113, 813

[65] Xu, T.; Hu, X. Angew. Chem., Int. Ed. 2015, 54, 1307.

[66] Guo, L.; Song, F.; Zhu, S.; Li, H.; Chu, L. Nat. Commun. 2018, 9, 4543.

[67] Li, H.; Guo, L.; Feng, X.; Huo, L.; Zhu, S.; Chu, L. Chem. Sci. 2020, 11, 4904.

[68] Zhu, C.; Yue, H.; Maity, B.; Atodiresei, I.; Cavallo, L.; Rueping, M. Nat. Catal. 2019, 2, 678.

[69] Yue, H.; Zhu, C.; Kancherla, R.; Liu, F.; Rueping, M. Angew. Chem., Int. Ed. 2020, 59, 5738.

[70] Zhang, Y.; Tanabe, Y.; Kuriyama, S.; Nishibayashi, Y. J. Org. Chem. 2021, 86, 12577.

[71] Xu, L.; Zhu, S.; Huo, L.; Chen, F.; Yu, W.; Chu, L. Org. Chem. Front. 2021, 8, 2924. 